BMC

Genomics

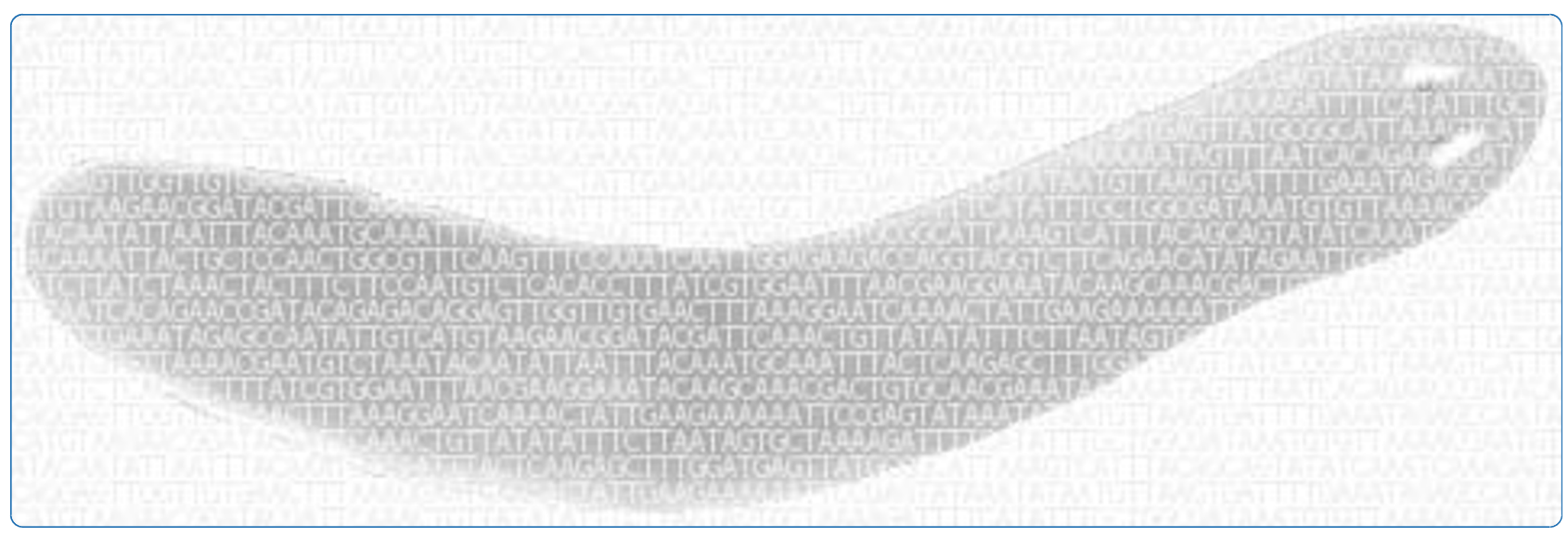

\title{
Smed454 dataset: unravelling the transcriptome of Schmidtea mediterranea
}

Abril et al. 


\title{
Smed454 dataset: unravelling the transcriptome of Schmidtea mediterranea
}

\author{
Josep F Abril ${ }^{1,2+}$, Francesc Cebrià ${ }^{1,2+}$, Gustavo Rodríguez-Esteban ${ }^{1,2}$, Thomas Horn ${ }^{3}$, Susanna Fraguas ${ }^{1,2}$, \\ Beatriz Calvo ${ }^{1,2}$, Kerstin Bartscherer ${ }^{4}$, Emili Salól, ${ }^{1 *}$
}

\begin{abstract}
Background: Freshwater planarians are an attractive model for regeneration and stem cell research and have become a promising tool in the field of regenerative medicine. With the availability of a sequenced planarian genome, the recent application of modern genetic and high-throughput tools has resulted in revitalized interest in these animals, long known for their amazing regenerative capabilities, which enable them to regrow even a new head after decapitation. However, a detailed description of the planarian transcriptome is essential for future investigation into regenerative processes using planarians as a model system.

Results: In order to complement and improve existing gene annotations, we used a 454 pyrosequencing approach to analyze the transcriptome of the planarian species Schmidtea mediterranea Altogether, 598,435 454sequencing reads, with an average length of $327 \mathrm{bp}$, were assembled together with the $\sim 10,000$ sequences of the S. mediterranea UniGene set using different similarity cutoffs. The assembly was then mapped onto the current genome data. Remarkably, our Smed454 dataset contains more than 3 million novel transcribed nucleotides sequenced for the first time. A descriptive analysis of planarian splice sites was conducted on those Smed454 contigs that mapped univocally to the current genome assembly. Sequence analysis allowed us to identify genes encoding putative proteins with defined structural properties, such as transmembrane domains. Moreover, we annotated the Smed454 dataset using Gene Ontology, and identified putative homologues of several gene families that may play a key role during regeneration, such as neurotransmitter and hormone receptors, homeoboxcontaining genes, and genes related to eye function.

Conclusions: We report the first planarian transcript dataset, Smed454, as an open resource tool that can be accessed via a web interface. Smed454 contains significant novel sequence information about most expressed genes of S. mediterranea. Analysis of the annotated data promises to contribute to identification of gene families poorly characterized at a functional level. The Smed454 transcriptome data will assist in the molecular characterization of S. mediterranea as a model organism, which will be useful to a broad scientific community.
\end{abstract}

\section{Background}

One of the challenges that medical research must address in the near future is to understand why some animals are able to regenerate complex structures, including eyes and even whole bodies, from small body fragments, while others are not. With the recent emergence of the field of regenerative medicine, the future

\footnotetext{
* Correspondence: esalo@ub.edu

+ Contributed equally

'Departament de Genètica, Facultat de Biología, Universitat de Barcelona (UB), Av. Diagonal 645, edifici annex, planta 1, 08028, Barcelona, Catalunya, Spain

Full list of author information is available at the end of the article
}

biomedical ramifications of the study of animal regeneration are obvious.

Freshwater planarians are a classic model for studying the fascinating process of regeneration [1-4] because they are capable of re-building a complete organism from almost any small body fragment. This is made possible by a unique population of adult somatic stem cells called neoblasts. During regeneration and constant homeostatic cell turnover, neoblasts differentiate into all cell types, including germ cells in sexual species $[5,6]$. In recent years, several studies have begun to unravel the mechanisms by which regeneration is regulated at the molecular level. For example, different genes have been
C Biomed Central

(C) 2010 Abril et al; licensee BioMed Central Ltd. This is an Open Access article distributed under the terms of the Creative Commons Attribution License (http://creativecommons.org/licenses/by/2.0), which permits unrestricted use, distribution, and reproduction in any medium, provided the original work is properly cited. 
shown to play pivotal roles in axon guidance and neurogenesis [7], the regulation of neoblast proliferation and differentiation $[8,9]$, and the re-establishment and maintenance of the anteroposterior (AP) and dorsoventral (DV) body axes [10]. Schmidtea mediterranea and Dugesia japonica are the two planarian species most often used in regeneration studies. There are about 78,000 ESTs (Expressed Sequence Tags) for $S$. mediterranea in NCBI generated in different projects $[11,12]$. Those sequences were clustered to produce a set of 10,000 putative mRNAs which are available from the NCBI Unigene database [13]. The S. mediterranea genome has also been sequenced and assembled [14] at the Genome Sequencing Center at Washington University in St. Louis (WUSL, USA) after approval of a white paper [15]. However, because of this genome's internal complexity $(67 \% \mathrm{~A}+\mathrm{T},[16])$ and the lack of a BAC library, its completeness and assembly still needs improvement. A step towards this end was taken when the $S$. mediterranea genome and EST information were integrated and approximately 30,000 genes were predicted using an annotation pipeline called MAKER [16]. Those gene models, together with $\sim 9,000$ mRNAs generated using next-generation sequencing technology, were mapped on the planarian genome and used to improve the assembly [17]. The current assembly contains 43,673 contigs. These are accessible, together with the MAKER annotation data, in the $S$. mediterranea genome database (SmedGD; [17])

In order to expand our knowledge of the planarian transcriptome and to provide a new tool that can be used to improve the $S$. mediterranea genome annotation, we generated a new transcriptome dataset using 454 pyrosequencing technology [18]. The Smed454 dataset can be freely accessed via a website, and the complete sequence data can be downloaded by anyone from there. Mapping of the Smed454 ESTs onto the genome scaffolds shows that the Smed454 dataset contains more than 3 million nucleotides sequenced de novo. In addition, this mapping extends and connects currently fragmented genomic contigs. Finally, GO annotation of the Smed454 dataset assigns candidate functions to those sequences and facilitates their grouping into distinct gene families. In this way, whole gene families can be analyzed for putative roles in planarian regeneration. Thus we are confident that the Smed454 dataset will improve our understanding of how planarian regeneration works at the molecular level.

\section{Results and Discussion}

\section{Construction and sequencing of the Smed454 dataset}

In order to obtain the most representative set of planarian genes expressed under different physiological conditions, total RNA was isolated from a mixture of non-irradiated and irradiated intact and regenerating planarians (see Methods). We used planarians regenerating both head and tail to identify the genes specifically expressed in a tissuespecific manner. Similarly, planarians at different stages of regeneration were used in order to isolate genes with different temporal expression profiles. Irradiation destroys planarian neoblasts within 1-2 days, and the animals die within a few weeks because they cannot sustain normal cell turnover. By including irradiated animals, potential transcripts specifically expressed under those conditions will be contained in the 454 dataset.

Using 454 pyrosequencing, 601,439 sequencing reads with an average length of 327 bp were obtained. After sequence cleaning to remove vector contamination, the remaining 598,435 sequences were assembled using different cut-off values for sequence similarity (90\%, 95\% and $98 \%$ ). In addition, our 454 sequence reads were assembled together with the $\sim 10,000 \mathrm{~S}$. mediterranea UniGene set available at NCBI, using the $90 \%$ similarity criteria. This last set, which was used in most of the analyses reported, is referred to as the 90e set. Table 1 summarizes the number of contigs and singletons obtained in each of those assemblies. The similarities between the three assemblies (90, 98 and 90e) are illustrated in Figure 1 a Venn diagram which shows that $72.68 \%$ of the raw sequencing reads were integrated into contigs common to all three assemblies, and $20.51 \%$ of the sequencing reads make up a shared pool of single sequencing reads (singletons). Therefore, differences between the assemblies can be explained by differential inclusion corresponding to $6.81 \%$ of the sequencing reads.

Average GC content and sequence length and their respective distributions were similar for all three assemblies (Table 1 and Figure 2). GC content is distributed around $35 \%$, the expected value for coding sequences in this species. The 90e length distribution shape was slightly shifted towards larger sequences. This shift was mainly due to a set of long sequences (>800 bp) from

Table 1 Summary of sequence statistics for each assembly.

\begin{tabular}{lllllllll}
\hline SET & Contigs & Singletons & $\begin{array}{c}\text { TOTAL } \\
\text { SEQs }\end{array}$ & GC\% & \multicolumn{3}{c}{$\begin{array}{c}\text { LENGTHs } \\
\text { [min/median/max/ } \\
\text { avg] }\end{array}$} \\
\hline $\mathbf{9 0}$ & 52,885 & 137,213 & 190,098 & 35.130 & 20 & 354 & 6812 & 355.78 \\
\hline $\mathbf{9 5}$ & 52,501 & 137,077 & 189,578 & - & - & - & - & - \\
\hline $\mathbf{9 8}$ & 52,321 & 137,353 & 189,674 & 35.127 & 20 & 354 & 6812 & 355.82 \\
\hline $\mathbf{9 0 e}$ & 53,867 & 138,766 & 192,633 & 35.108 & 20 & 358 & 7918 & 364.81 \\
\hline
\end{tabular}

Set names are related to the corresponding homology level cutoff value (90e stands for $90 \%$ similarity including the set of NCBI Unigene ESTs). Contigs are the result of at least two sequencing reads, and singletons of only one read. $\mathrm{GC}$ content is the average value for all sequences. Sequence lengths are shown as minimum, median, maximum and average values in nucleotides for each set. 


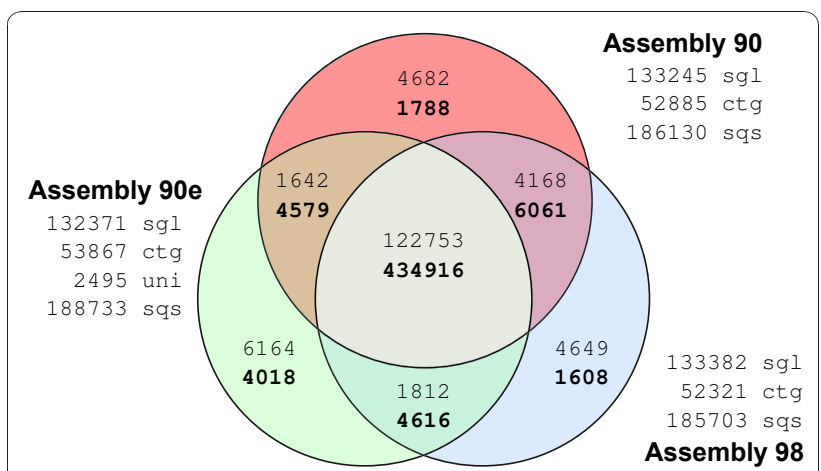

Figure 1 Overlap-analysis of Smed454 assemblies. Comparison of the 454-sequencing reads taken into account to build each Smed454 dataset. Venn-diagram numbers in plain format correspond to singleton reads, while numbers in bold correspond to sequencing reads that were assembled into Contigs. About 4,000 raw reads where split into two or more fragments, due to quality clipping. However, only distinct raw read identifiers, after removing the fragment suffix, were used to produce this figure. sgl: total number of singletons for that assembly; ctg: total number of contigs; uni: number of NCBI Unigene sequences not assembled into a contig (90e only); sqs: total number of sequences for a given dataset.

the NCBI Unigene ESTs included in this assembly. This causal relationship was evident in the comparison of the following four subsets of sequences from the 90e set (lightblue violin plots on Figure 2 right panel): singletons $(136,271)$, contigs that do not contain UniGene ESTs $(46,958)$, contigs including Unigene ESTs $(6,909)$,

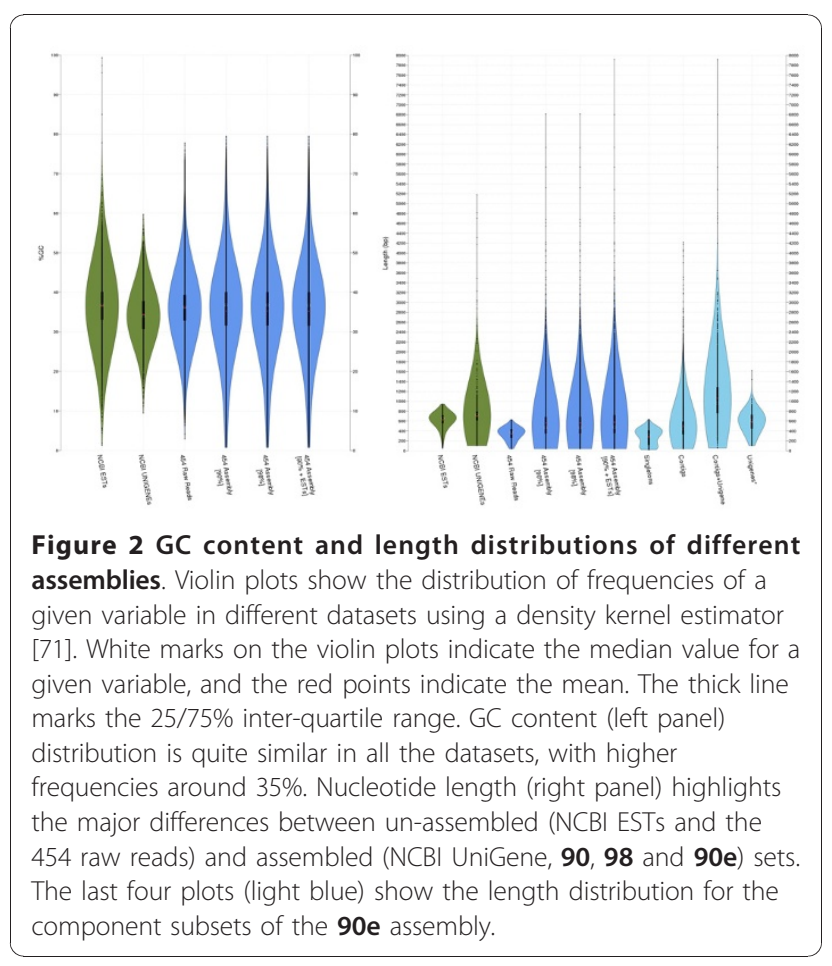

and finally, Unigene ESTs not assembled into a contig $(2,495)$.

\section{Mapping the 90e assembly onto the genome}

The 90e assembly (192,633 sequences, 70,274,612 bases in total, average length of $365 \mathrm{bp}$ per sequence) was aligned to scaffolds from the $S$. mediterranea WUSL genome assembly, version 3.1 [14] (43,294 sequences, $901,626,601$ bases in total, average length of 20,8 kilobases per scaffold). Figure 3 shows all possible highscoring segment pair (HSP) relationships between those two sequence sets. From almost 30 million initial HSPs, around 7 million were selected using a combination of thresholds, as described in the Methods section. Discarding singleton sequences in a second round of filtering further reduced the number of HSPs to 5 million, and HSP coverage dropped from $25.36 \%$ and $77.24 \%$, for scaffolds and 90e respectively, to $10.57 \%$ and $37.93 \%$. However, when the total nucleotide length was considered only for the contigs (56,363 sequences, 32,518,399 bases in total, with an average of 577 bp per sequence), HSP coverage for 90 e rose to $81.97 \%$. This means that most of the significant HSP hits are retained after the second round of filtering. In total, 8,831 contigs from 90e did not map to the genomic contigs $(3,242,054 \mathrm{bp}$ that are completely novel and also transcribed, see column A in Figure 3). Conversely, 5,138 genomic contigs did not match a sequence from 90e (column B). Of the 90e contigs, 322 extended a genomic sequence from the left (column C) and 3,051 from the right (column J). The largest intergenic distance was $42,209 \mathrm{bp}$, with an average value of 1,102 bp (column $\mathrm{H}$ ). The largest intron was estimated to be about 9,300 bp, the average length being $238 \mathrm{bp}$ (column E). Finally, there were 20,504 HSPs connecting different genomic sequences via 8,604 different 90e contigs (column I). Of the 8,831 90e contigs not found on the genome, 3,480 had a BLAST hit to the NCBI NR protein database (39.41\%), and, of those, 2,401 had a hit to a protein with GO annotation (27.19\%). After discarding abundant actin-like sequences (1,503), ATP/ADP transporter proteins (722) and sequences matching bacterial, protozoan or fungal genes (1,234), 71 90e contigs remained as new sequences not mapping on the genome (see Additional File 1).

In order to validate exonic structures, 6,226 90e contigs mapping 1-to-1 over genome sequences were selected. After re-aligning the 90e/genomic sequence pairs, 4,739 contained at least one putative intron (see the corresponding splice sites boundaries in Additional File 2). In total 8,609 introns were retrieved from the genomic contigs. Figure 4 shows the number of introns per 90e contig, as well as the length distribution for those introns. Pictograms summarize the nucleotide frequencies for the donor and acceptor splice sites, both 


\begin{tabular}{|c|c|c|c|c|c|c|c|c|c|c|c|}
\hline & \multicolumn{2}{|c|}{ Genomic } & \multicolumn{3}{|c|}{ 454-Contigs } & \multirow[t]{2}{*}{ \#HSPs } & \multicolumn{3}{|c|}{ HSP Coverage (bp) } & \\
\hline & & \#Contigs & Length (bp) & \#Contigs & \multicolumn{2}{|c|}{ Length (bp) } & & Genomic & \multicolumn{2}{|c|}{ 454-Contigs } & \\
\hline \multicolumn{2}{|c|}{ Raw HSPs } & 43,294 & $901,626,601$ & 192,6 & 633 & 274,612 & $29,591,553$ & $228,670,049$ & $54,27 €$ & 6,468 & \\
\hline \multicolumn{2}{|c|}{ Filtered HSPs } & id. & id. & & id. & id. & $7,213,095$ & $166,984,912$ & 52,83 & 1,633 & \\
\hline \multicolumn{2}{|c|}{ Seqs $>100 b p$ HSPs } & id. & id. & 160,4 & 424 & 607,171 & $7,173,215$ & $166,440,678$ & 52,83 & 1,633 & \\
\hline \multicolumn{2}{|c|}{ 454-Contig HSPs } & id. & id. & 56,3 & 362 & 518,399 & $5,114,385$ & $95,338,807$ & 26,656 & 6,481 & \\
\hline \multicolumn{12}{|c|}{454 CONTIGS } \\
\hline \multicolumn{12}{|l|}{ HSPS } \\
\hline \multicolumn{12}{|l|}{ GENOMIC } \\
\hline \multicolumn{12}{|l|}{ Raw HSPs } \\
\hline \#HSPs & 47,593 & 1,332 & 48,211 & 463,343 & 28,806 & $6,071,351$ & 29,276 & $3,344,064$ & 150,005 & & 7,941 \\
\hline Sum Length (bp) & $10,199,565$ & $5,077,054$ & 354,640 & $12,950,980$ & $1,107,729$ & $150,053,495$ & - & $613,633,754$ & $2,773,546$ & 2,09 & 9,794 \\
\hline Avg Length (bp) & 214.31 & $3,811.60$ & 7.36 & 27.95 & 38.45 & 24.72 & - & 183.50 & 18.49 & & 24.02 \\
\hline Max Length (bp) & - & - & - & 1,482 & 9,341 & 2,771 & - & 35,264 & 1,232 & & - \\
\hline \multicolumn{12}{|l|}{ Filtered HSPs } \\
\hline \#HSPS & 63,199 & 2,554 & 800 & 27,303 & 9,251 & 653,552 & 8,763 & $1,064,390$ & 28,122 & & 0,261 \\
\hline Sum Length (bp) & $12,096,027$ & $9,434,489$ & 147,970 & $1,027,711$ & $1,454,836$ & $32,147,178$ & - & $650,861,301$ & 835,969 & 2,06 & 8,647 \\
\hline Avg Length (bp) & 191.40 & $3,694.01$ & 184.96 & 37.64 & 157.26 & 49.19 & - & 611.49 & 29.73 & 2,01 & 60.29 \\
\hline Max Length (bp) & - & - & - & 1,314 & 9,381 & 2,771 & - & 35,458 & 1,085 & & - \\
\hline \multicolumn{12}{|l|}{ Seqs $>100 b p$ HSPs } \\
\hline \#HSPS & 30,990 & 2,589 & 800 & 27,302 & 9,373 & 653,440 & 8,751 & $1,055,195$ & 28,122 & & 0,261 \\
\hline Sum Length (bp) & $10,428,586$ & $9,573,977$ & 147,970 & $1,027,643$ & $1,452,968$ & $32,139,918$ & - & $650,215,159$ & 835,969 & 2,06 & 8,647 \\
\hline Avg Length (bp) & 336.51 & $3,697.94$ & 184.96 & 37.64 & 155.02 & 49.19 & - & 616.20 & 29.73 & & 01.60 \\
\hline Max Length (bp) & - & - & - & 1,314 & 9,381 & 2,771 & - & 35,458 & 1,085 & & - \\
\hline \multicolumn{12}{|l|}{ 454-Contig HSPs } \\
\hline \#HSPs & 8,831 & 5,138 & 322 & 18,424 & 13,849 & 356,049 & 8,141 & 603,099 & 20,504 & & 3,051 \\
\hline Sum Length (bp) & $3,242,054$ & $20,729,794$ & 91,957 & 763,088 & $3,294,897$ & $19,895,116$ & - & $664,430,022$ & 540,756 & & 5,169 \\
\hline Avg Length (bp) & 367.12 & $4,034.60$ & 285.58 & 41.42 & 237.92 & 55.88 & - & $1,101.69$ & 26.37 & & 31.13 \\
\hline Max Length (bp) & - & - & - & 1,314 & 35,641 & 2,771 & - & 42,209 & 1,085 & & - \\
\hline \multicolumn{12}{|c|}{$\begin{array}{l}\text { Figure } 3 \text { Distribution of different HSP types from 90e over genome sequences. The top table shows the total number of similarity hits, } \\
\text { while the bottom table classifies the hits into different types of HSPs: A) } 454 \text { contigs not mapping to a genomic sequence; B) genomic contigs } \\
\text { not mapping to a } 454 \text { contig; C and J) } 454 \text { contigs with an unmapped sequence on the left and right, respectively; D) missing sequence on } 454 \\
\text { contigs corresponding to a putative gap in the assembly; E) contiguous HSPs on } 454 \text { contigs related to a genomic intron; F) co-linear } \\
\text { unmapped sequences on both sequence sets; G) contiguous overlapping HSPs defining a larger similarity segment; H) unaligned genomic } \\
\text { sequences between HSPs of two different } 454 \text { contigs, which can be interpreted as putative intergenic sequences; I) HSPs on } 454 \text { contigs } \\
\text { supporting a pair of genomic contigs, which could then be merged into a larger genomic scaffold. All columns show HSP numbers-the '\#HSPs' } \\
\text { row-except for A and B, which correspond to number of sequences. }\end{array}$} \\
\hline
\end{tabular}

for the U2 (canonical) and U12 (non-cannonical) introns. The splice sites patterns resemble those from other metazoan [19], taking into account that the genome of S.mediterranea is A/T-rich [16].

Also, 50 randomly picked 90 e contigs that either mapped or did not map to the genome were validated by RT-PCR (see Additional File 3 containing a list of the selected 90e contigs, as well as information on the primers used to amplify them). Additionally, 20 out of those 50 genes were further validated by sequencing. Finally, to further confirm the quality and coverage of the sequences from the 90e dataset, the $S$. mediterranea genes already annotated in NCBI GenBank [20] were compared with those sequences. After discarding $18 \mathrm{~S}$ and $28 \mathrm{~S}$ ribosomal RNA genes and alpha-tubulins, 124 known genes were aligned to the $90 \mathrm{e}$ sequences. In total, 108 of these genes had at least one significant similarity hit with one 90e sequence, and two matched 5 sequences from 90e. On average, the known genes had co-linear similarity hits against 1.32 different Smed454 sequences. Minimum and average similarities were $8.35 \%$ and $85.34 \%$ respectively, and 71 sequences had more than $95 \%$ similarity. Mean coverage dropped to $77.63 \%$ when each hit was considered separately. A summary of these similarity analyses is shown in Additional File 4.

\section{Browsing the Smed454 dataset}

In order to make the Smed454 dataset useful and accessible to the planarian and non-planarian communities, a public database is available via web [21]. The web site allows users to view contig assemblies along with their read alignments, and to perform BLAST searches against assembled 

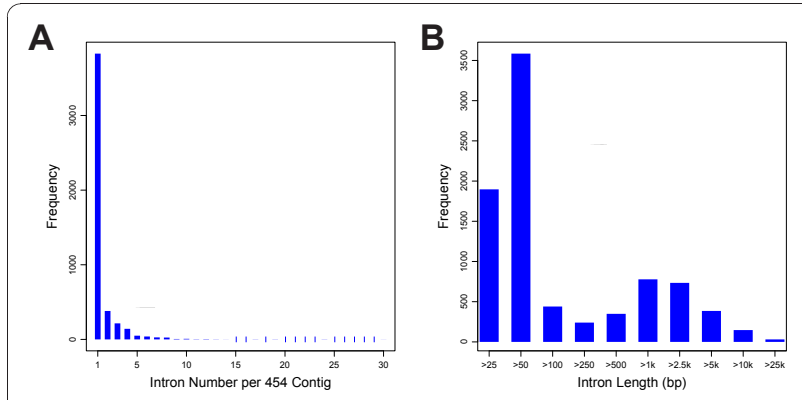

C

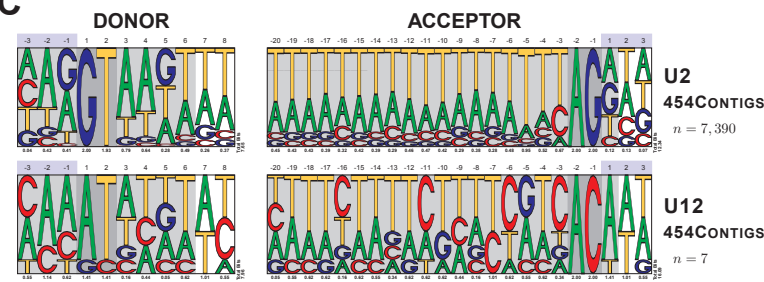

Figure 4 Analysis of intronic features and splice sites on a set of 90 e contigs. A) Distribution of the number of putative introns per 90 e contig. B) Length distribution of putative introns. C) Pictograms summarizing the consensus donor and acceptor splice sites for the predicted introns. $n$ corresponds to the number of intron sequences used to compute the nucleotide position weight matrices for the pictograms. Light grey shadowed regions correspond to the commonly used signal lengths for gene-finding, while dark grey ones define the nucleotide boundaries of the introns. Numbers below pictograms are the bit-scores that describe the information content per position.

sequences. The BLAST option in the home page menu ( 1 in Figure 5 ) allows the user to BLAST sequences of interest against the 90, 98, and 90e databases (1.2 in Figure $5)$. Both nucleotide (BLASTN) and protein (BLASTP) searches can be performed (1.1 in Figure 5). Clicking on the Search button (1.3 in Figure 5) brings up a new window displaying a list of hits. When a score value is selected (1.4 in Figure 5), the alignment between the query sequence and the Smed454 hit is shown. The site also offers the option of downloading Smed454 sequences of interest (1.5 in Figure 5). The contig or singleton accession number can be browsed directly from the main home page ( 2 in Figure $5)$. When the user searches for a specific contig, a new window appears showing the alignment of all the sequencing reads assembled in that contig. At the bottom of that window, the result of a pre-computed BLAST on the contig consensus sequence is displayed. When a contig, singleton or read name is selected (2.1 in Figure 5), a new window will display the requested sequence. All raw and assembled sequence data are available from that web site too.

\section{Functional annotation of 90e sequences}

In order to characterize the gene families that can be found on Smed454, we annotated the three datasets; we will focus on 90 e dataset here. In total, $42.42 \%$ of the sequences had a similarity hit with at least one protein sequence in the NCBI NR protein database [20]. Of these, almost two-thirds had 250 or more hits (see Figure 6), but the BLASTX output was limited to a maximum of 250 hits per 90e sequence owing to the large number of HSPs reported by BLAST for some of them. The Gene Ontology (GO) [22] database was used to computationally annotate all the sequences (see Additional File 5 for 90, 98, and 90e datasets) by mapping onto them the functional codes already assigned to known proteins from NCBI NR. Many of these sequence hits matched to a short ATP-binding domain, in most cases corresponding to proteins of the actins family. Consequently, that functional class, which was also anomalously over-represented, was discarded from the total number of annotations for the 90e set, as shown in Table 2.

Among the most abundant GO annotations at the biological process level, leaving aside metabolism-related features, 'response to stress' was found for 1,070 sequences (6.58\%). This finding was expected because the original biological sample was a mixture of intact and regenerating planarians, both normal and irradiated. 'Regulation of biological process' was in the same range, with 1,012 sequences (6.22\%). At the GO molecular function level, 'binding' was the most common annotation, although where possible a more specific annotion was provided by drilling down to the $2^{\text {nd }}$ level child annotations on the GO graph. It is interesting to find, among others, 3 'selenium binding' activities, since it has been reported that selenium may play an important role in cancer prevention, immune system function, male fertility, cardiovascular and muscle disorders, and prevention and control of the ageing process [23]. Finding selenium-binding proteins would be evidence of the presence of selenoproteins, which are thought to be responsible for most of the biomedical effects of selenium across eukaryota [24]. When looking at the cellular component level and discarding many of the 'intracellular organelles' due to their co-occurrence with 'nucleotide binding', there are a notably large number of 'protein complexes', 2,918 sequences (40.79\%). With 819 sequences (11.45\%), another important term on this level is 'vesicle', which correlates with secretory functions, apoptosis, and autophagy.

To prove the usefulness of the Smed454 dataset, we performed several searches on specific groups and gene families for which only scant data has been reported to date in planarians. Planarians are mainly known for their remarkable regenerative capabilities, which depend upon the presence of stem cells named neoblasts. Because of the unique properties of these cells, some studies have used a microarray-based strategy to detect neoblast-specific genes $[25,26]$. In our Smed454 dataset we were able to identify, in addition to known neoblast 


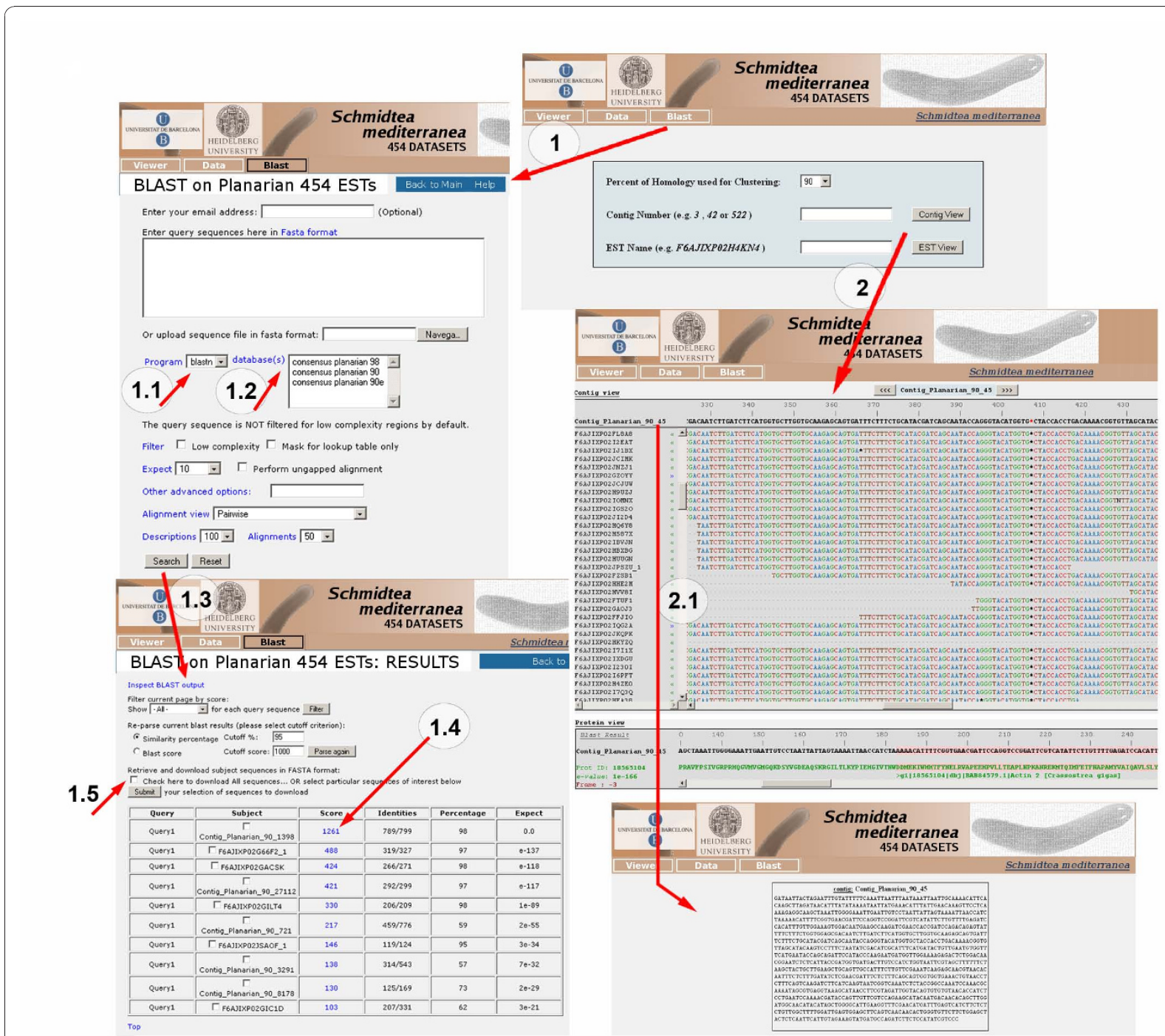

Figure 5 The content of the Smed454 web site. Screenshots of the pages that facilitate access to the three sequence assemblies $(\mathbf{9 0}, \mathbf{9 8}$ and 90e), including the page displaying alignments of raw reads. A BLAST interface, adapted from NBCl's toolkit, is also available for querying the sequences from the datasets. The web site is available at http://planarian.bio.ub.es/datasets/454/.

markers such as piwis, histones, bruli, vasa or tudor, several other genes annotated as involved in cell cycle or DNA damage and repair (Additional File 6). Within these gene set we find many cyclins and cell cycle division-related genes but also genes related to replication and chromosome maintenance. Finally, genes related to stress response and DNA damage were also identified, probably owing to the use of irradiated animals in the generation of the Smed454 dataset. In addition to these neoblast-related genes we were able to identify large collections of much less well-characterized families in planarians, such as neurotransmitter, peptide and hormone receptors, homeobox domain-containing genes, and genes related to eye function in other animals.

\section{Prediction of planarian transmembrane proteins}

Transmembrane (TM) proteins regulate a number of biological processes ranging from catalytic processes in intracellular and extracellular transport to cell-to-cell communication. TM proteins have become particularly interesting as many of them are key initiators of signal transduction pathways, and they can be easily manipulated by small molecule- or antibody-based drugs. To identify putative TM proteins from the planarian transcriptome, we mined the 454 dataset for putative TM protein-encoding messages (see Methods). Considering only the proteins that at least two application predicted would contain one or more transmembrane domains, resulted in a list of 8,597 predicted transmembrane 


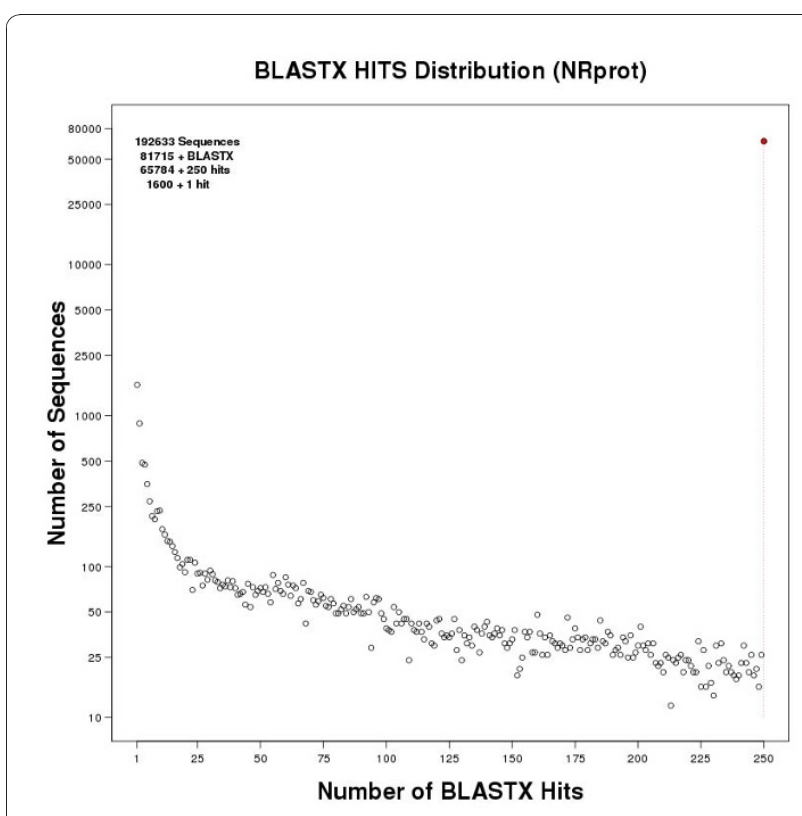

Figure 6 Distribution of BLASTXhits of 90e sequences against NCBI NRprot. Sequences from the $\mathbf{9 0 e}$ dataset were compared against the NCBI NR protein database using BLASTX. The figure shows the distribution of the number of sequences binned by the number of HSPs they had. Y-axis in log scale.

proteins (see Figure 7a), which represents $15,3 \%$ of the complete protein database. Protein-BLAST searches were then used to align sequences to each other, and redundant sequences were removed from the predicted transmembrane set. The resulting database contained 4,663 sequences. Functional categorization using the UFO webserver [27] allowed us to assign PFAM protein families to 1,474 of the sequences and gene ontology classifications to 2,464 . The top ten PFAM domains ( $33 \%$ of all assignments) included, for example, the classifications for 'major facilitator superfamily' (a ubiquitous transporter family), '7 transmembrane receptor (rhodopsin family)' and 'ion transport protein' (see Figure 7b). The top ten gene ontology profiles ( $49 \%$ of all assignments) included 'membrane' (cellular component), 'transport', and 'G-protein coupled receptor protein signalling pathway' (both biological processes, see Figure 7c). The enrichment of our database with proteins that have a predicted function in transport and receptor signalling supports the reliability of our approach. A complete list of the 4,663 predicted transmembrane proteins, the number of predicted transmembrane domains, predicted topology, and functional categorizations (PFAM and GO) are shown in Additional File 7.

\section{Neurotransmitter and hormone receptors in Schmidtea mediterranea}

Despite our growing knowledge about how planarian neoblasts are regulated at the molecular level $[9,25,26,28-31]$, we are still far from characterizing the complete repertoire of factors that control neoblast biology. Receptors for neurotransmitters, peptides and hormones are among the candidates for a role in the regulation of neoblast proliferation, differentiation and migration. In planarians, some of the data suggest that molecules such as dopamine [32,33], serotonin [34], substance P [35], somatostatin [36] and FMRFamide [37] can accelerate or delay the regeneration rate, probably by regulating neoblast proliferation and/or differentiation. A model has been proposed in which neoblasts express receptors for some of these factors, which in turn regulate the fate of these cells [35]. We found 288 contigs and singletons in the annotated Smed454 dataset with significant homology to neurotransmitter and hormone receptors (Table 3 and Additional File 8), providing a list of potentially interesting candidates.

\section{Homeobox-containing sequences in Schmidtea mediterranea}

Since the first homeobox-containing genes were characterized in planarians [38], a large number of Hox and ParaHox genes that could be accommodated into the classical series of paralogous groups from Plhox1 to Plohox-9 and Xlox to cad/Cdx $[39,40]$ have been described. Some of them show a differentially axial nested expression; while others are ubiquitously expressed [41-43]. Most of this work has been done in the planarians Girardia tigrina and Dugesia japonica. Recently, the first expression of an $S$. mediterranea Hox gene has been reported [44]. We identified 50 contigs and singletons with significant sequence similarity to homeobox gene sequences in the annotated Smed545 dataset (Table 4), including Hox genes and homeobox-containing genes, some already characterized in other planarian species.

\section{Eye genes in Schmidtea mediterranea}

The structural simplicity of the planarian eye in conjunction with the regenerative abilities of these organisms provides a unique system for dissecting the genetic mechanisms that allow a simple visual structure to be built $[45,46]$. Despite great morphological differences, there is evidence that the early morphogenesis of animal eyes requires the regulatory activity of Pax6, Sine oculis (Six), Eyes absent (Eya) and Dachshund (Dach), a gene network known as the retinal determination gene network (RDGN) [47-50]. Most of the genetic elements of the RDGN have been characterized in planarians [51-54]. In addition, the following planarian genes have been identified as being involved in eye regeneration: Djeye53, Dj1020HH [55]; Smed-netR, Smed-netrin2 [56]; Gt/Smed/Dj ops [46,57]; Djsnap-25 [58]; and Smednos [59]. In order to characterize new $S$. mediterranea eye network genes, we analyzed the Smed454 annotated 
Table 2 Gene Ontology annotation for 90 e set sequences.

\begin{tabular}{|c|c|c|c|c|c|c|c|c|c|c|c|}
\hline GO & $\begin{array}{l}\text { Molecular } \\
\text { Function }\end{array}$ & Count & $\begin{array}{r}\text { Freq } \\
\%\end{array}$ & GO & Biological Process & Count & $\begin{array}{r}\text { Freq } \\
\%\end{array}$ & GO & $\begin{array}{l}\text { Cellular } \\
\text { Component }\end{array}$ & Count & $\begin{array}{r}\text { Freq } \\
\%\end{array}$ \\
\hline GO:0000166 & $\begin{array}{l}\text { nucleotide } \\
\text { binding }\end{array}$ & 54,823 & - & - & - & - & - & GO:0043229 & $\begin{array}{l}\text { intracellular } \\
\text { organelle }\end{array}$ & 60,817 & - \\
\hline - & unannotated & 9,709 & - & - & unannotated & 62,834 & - & - & unannotated & 11,131 & - \\
\hline GO:0016787 & hydrolase activity & 5,197 & 35.669 & GO:0043170 & $\begin{array}{l}\text { macromolecule } \\
\text { metabolic process }\end{array}$ & 5,793 & 35.610 & GO:0043234 & $\begin{array}{l}\text { protein } \\
\text { complex }\end{array}$ & 2,918 & 40.788 \\
\hline GO:0016740 & transferase activity & 2,030 & 13.933 & GO:0022607 & $\begin{array}{l}\text { cellular component } \\
\text { assembly }\end{array}$ & 2,182 & 13.413 & GO:0044424 & $\begin{array}{l}\text { intracellular } \\
\text { part }\end{array}$ & 2,314 & 32.346 \\
\hline GO:0043167 & ion binding & 1,323 & 9.080 & GO:0006810 & transport & 1,213 & 7.456 & GO:0031982 & vesicle & 819 & 11.448 \\
\hline GO:0003735 & $\begin{array}{l}\text { structural } \\
\text { constituent of } \\
\text { ribosome }\end{array}$ & 874 & 5.999 & GO:0006950 & response to stress & 1,070 & 6.577 & GO:0044425 & $\begin{array}{l}\text { membrane } \\
\text { part }\end{array}$ & 469 & 6.556 \\
\hline GO:0005488 & binding & 761 & 5.223 & GO:0050789 & $\begin{array}{l}\text { regulation of } \\
\text { biological process }\end{array}$ & 1,012 & 6.221 & GO:0016020 & membrane & 210 & 2.935 \\
\hline GO:0016491 & $\begin{array}{l}\text { oxidoreductase } \\
\text { activity }\end{array}$ & 703 & 4.825 & GO:0006807 & $\begin{array}{l}\text { nitrogen compound } \\
\text { metabolic process }\end{array}$ & 722 & 4.438 & GO:0005622 & intracellular & 111 & 1.552 \\
\hline GO:0022857 & $\begin{array}{l}\text { transmembrane } \\
\text { transporter activity }\end{array}$ & 678 & 4.653 & GO:0048869 & $\begin{array}{l}\text { cellular } \\
\text { developmental } \\
\text { process }\end{array}$ & 655 & 4.026 & GO:0044446 & $\begin{array}{l}\text { intracellular } \\
\text { organelle part }\end{array}$ & 91 & 1.272 \\
\hline GO:0030235 & $\begin{array}{l}\text { nitric-oxide } \\
\text { synthase regulator } \\
\text { activity }\end{array}$ & 597 & 4.097 & GO:0065009 & $\begin{array}{l}\text { regulation of } \\
\text { molecular function }\end{array}$ & 622 & 3.823 & GO:0005576 & $\begin{array}{l}\text { extracellular } \\
\text { region }\end{array}$ & 63 & 0.881 \\
\hline GO:0043176 & amine binding & 580 & 3.981 & GO:0009056 & catabolic process & 507 & 3.117 & GO:0045211 & $\begin{array}{l}\text { postsynaptic } \\
\text { membrane }\end{array}$ & 21 & 0.294 \\
\hline GO:0005515 & protein binding & 532 & 3.651 & GO:0044419 & $\begin{array}{l}\text { interspecies } \\
\text { interaction between } \\
\text { organisms }\end{array}$ & 280 & 1.721 & GO:0044420 & $\begin{array}{l}\text { extracellular } \\
\text { matrix part }\end{array}$ & 19 & 0.266 \\
\hline GO:0003676 & $\begin{array}{l}\text { nucleic acid } \\
\text { binding }\end{array}$ & 401 & 2.752 & GO:0055114 & oxidation reduction & 236 & 1.451 & GO:0043233 & $\begin{array}{l}\text { organelle } \\
\text { lumen }\end{array}$ & 18 & 0.252 \\
\hline GO:0005215 & transporter activity & 387 & 2.656 & GO:0065008 & $\begin{array}{l}\text { regulation of } \\
\text { biological quality }\end{array}$ & 206 & 1.266 & GO:0031012 & $\begin{array}{l}\text { extracellular } \\
\text { matrix }\end{array}$ & 16 & 0.224 \\
\hline GO:0016829 & lyase activity & 71 & 0.487 & GO:0048856 & $\begin{array}{l}\text { anatomical structure } \\
\text { development }\end{array}$ & 193 & 1.186 & GO:0042597 & $\begin{array}{l}\text { periplasmic } \\
\text { space }\end{array}$ & 15 & 0.210 \\
\hline GO:0016853 & isomerase activity & 55 & 0.377 & GO:0051649 & $\begin{array}{l}\text { establishment of } \\
\text { localization in cell }\end{array}$ & 183 & 1.125 & GO:0000267 & cell fraction & 15 & 0.210 \\
\hline GO:0048037 & cofactor binding & 52 & 0.357 & GO:0044237 & $\begin{array}{l}\text { cellular metabolic } \\
\text { process }\end{array}$ & 182 & 1.119 & GO:0044462 & $\begin{array}{l}\text { external } \\
\text { encapsulating } \\
\text { structure part }\end{array}$ & 11 & 0.154 \\
\hline GO:0016874 & ligase activity & 49 & 0.336 & GO:0023060 & signal transmission & 150 & 0.922 & GO:0031975 & envelope & 8 & 0.112 \\
\hline GO:0004871 & $\begin{array}{l}\text { signal transducer } \\
\text { activity }\end{array}$ & 45 & 0.309 & GO:0048870 & cell motility & 141 & 0.867 & GO:0005615 & $\begin{array}{l}\text { extracellular } \\
\text { space }\end{array}$ & 7 & 0.098 \\
\hline GO:0003824 & catalytic activity & 32 & 0.220 & GO:0008152 & metabolic process & 139 & 0.854 & GO:0009986 & cell surface & 6 & 0.084 \\
\hline GO:0060589 & $\begin{array}{l}\text { nucleoside- } \\
\text { triphosphatase } \\
\text { regulator activity }\end{array}$ & 32 & 0.220 & GO:0023033 & signaling pathway & 107 & 0.658 & GO:0043204 & perikaryon & 5 & 0.070 \\
\hline GO:0042277 & peptide binding & 28 & 0.192 & GO:0044238 & $\begin{array}{l}\text { primary metabolic } \\
\text { process }\end{array}$ & 83 & 0.510 & GO:0030427 & $\begin{array}{l}\text { site of } \\
\text { polarized } \\
\text { growth }\end{array}$ & 4 & 0.056 \\
\hline GO:0022892 & $\begin{array}{l}\text { substrate-specific } \\
\text { transporter activity }\end{array}$ & 22 & 0.151 & GO:0042221 & $\begin{array}{l}\text { response to chemical } \\
\text { stimulus }\end{array}$ & 69 & 0.424 & GO:0042995 & cell projection & 3 & 0.042 \\
\hline GO:0019208 & $\begin{array}{l}\text { phosphatase } \\
\text { regulator activity }\end{array}$ & 12 & 0.082 & GO:0006996 & $\begin{array}{l}\text { organelle } \\
\text { organization }\end{array}$ & 47 & 0.289 & GO:0030312 & $\begin{array}{l}\text { external } \\
\text { encapsulating } \\
\text { structure }\end{array}$ & 2 & 0.028 \\
\hline GO:0003712 & $\begin{array}{l}\text { transcription } \\
\text { cofactor activity }\end{array}$ & 12 & 0.082 & GO:0007017 & $\begin{array}{l}\text { microtubule-based } \\
\text { process }\end{array}$ & 42 & 0.258 & GO:0031594 & $\begin{array}{l}\text { neuromuscular } \\
\text { junction }\end{array}$ & 2 & 0.028 \\
\hline GO:0019207 & $\begin{array}{l}\text { kinase regulator } \\
\text { activity }\end{array}$ & 11 & 0.075 & GO:0044281 & $\begin{array}{l}\text { small molecule } \\
\text { metabolic process }\end{array}$ & 39 & 0.240 & GO:0045177 & $\begin{array}{l}\text { apical part of } \\
\text { cell }\end{array}$ & 2 & 0.028 \\
\hline GO:0008289 & lipid binding & 9 & 0.062 & GO:0051301 & cell division & 37 & 0.227 & GO:0019028 & viral capsid & 1 & 0.014 \\
\hline
\end{tabular}


Table 2 Gene Ontology annotation for 90e set sequences. (Continued)

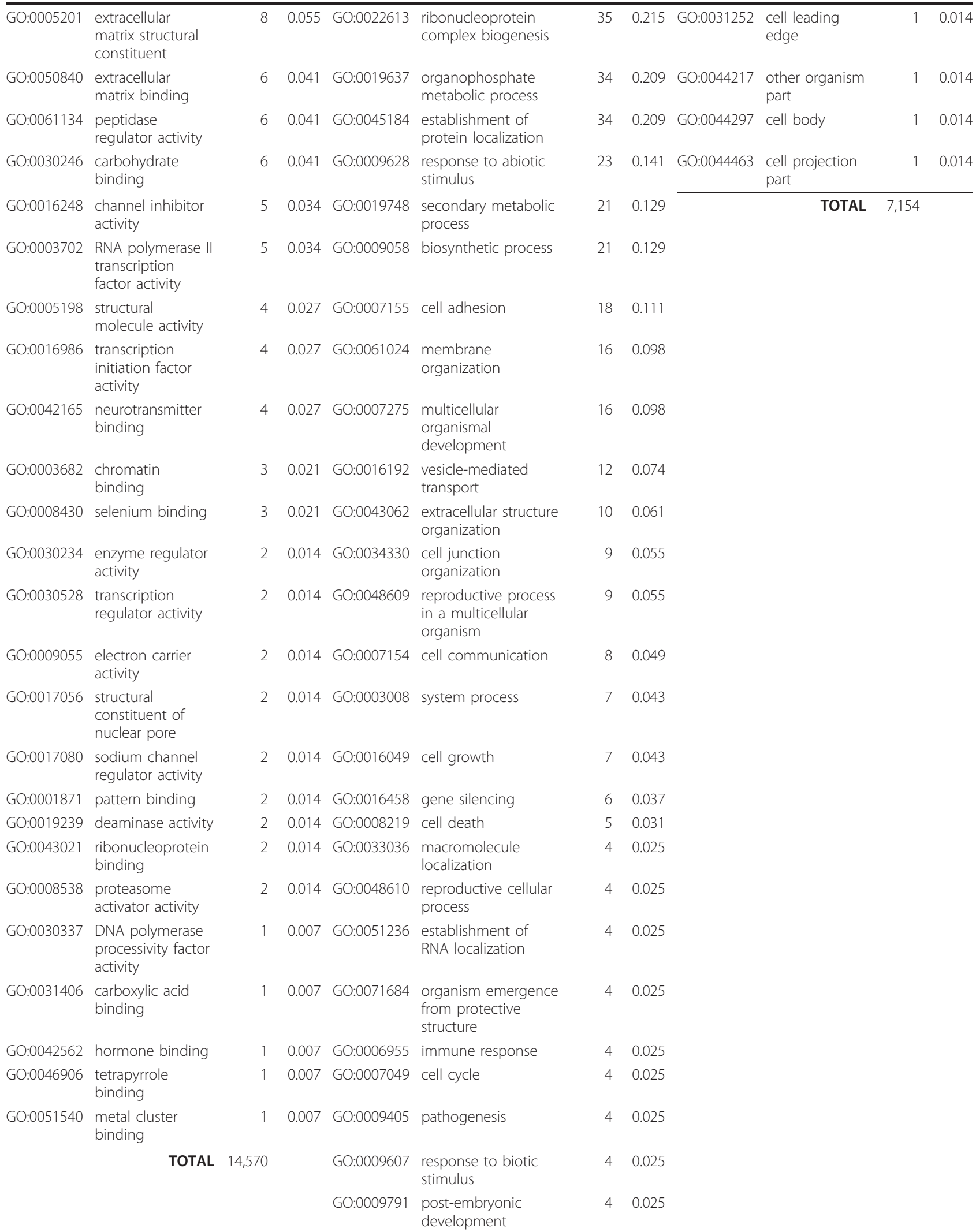


Table 2 Gene Ontology annotation for 90 e set sequences. (Continued)

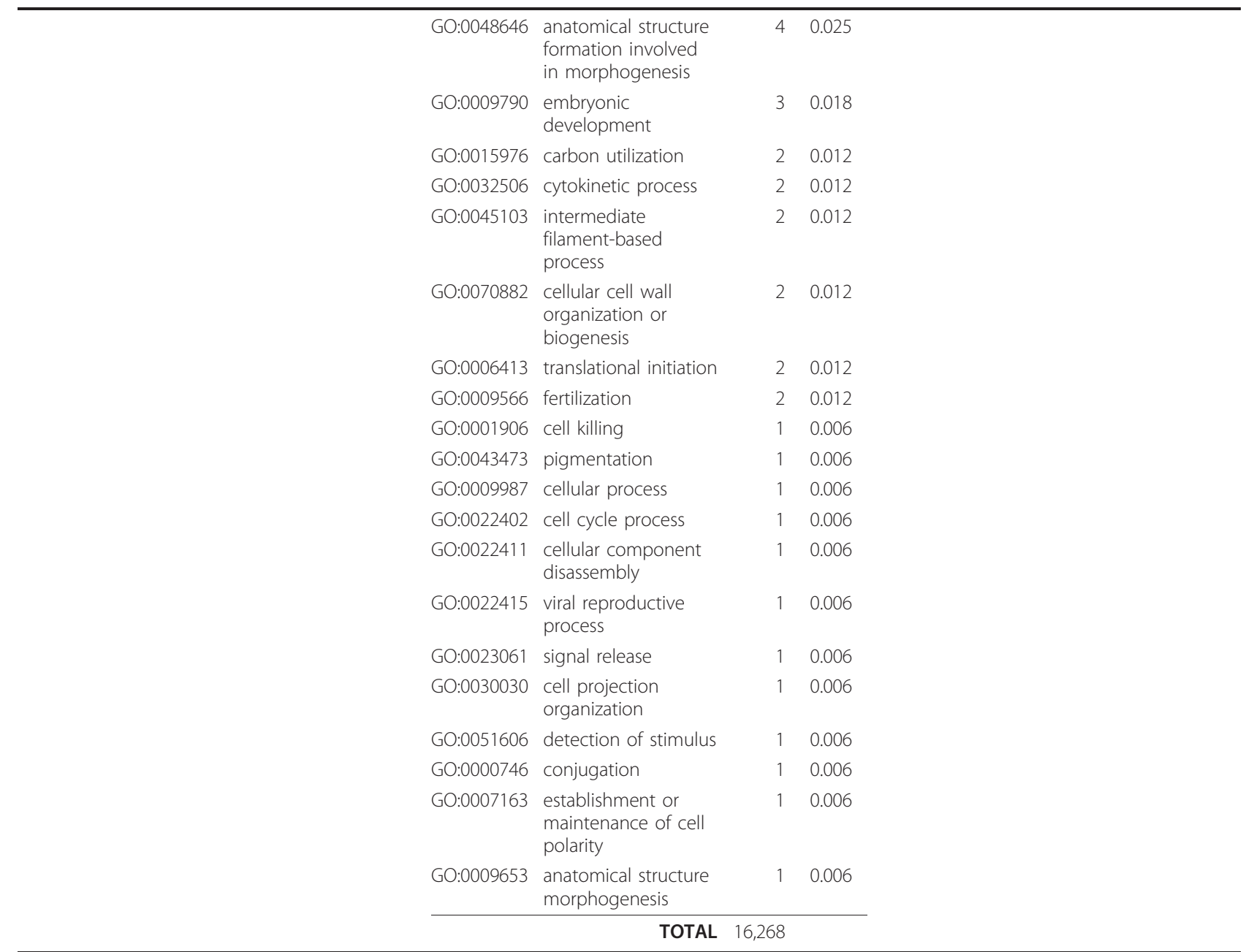

The most probable GO code in the three ontology categories-molecular function, biological process and cellular component- for each sequence in the 90 e data set was selected. For simplicity, only level one and two codes are shown here in order.

dataset and found a collection of genes, ranging from transcription factors to eye-realizator genes, which have been implicated in eye development in other systems. These are good candidates for expanding our knowledge about the genetic network responsible for planarian eye regeneration (Table 5 and Additional File 9).

\section{Conclusions}

The inherent complexity of the planarian genome and methodological difficulties initially prevented the complete genome assembly of $S$. mediterranea. High-throughput sequencing technologies are now well established and help molecular biologists to unravel the molecular components of organisms. We present a 454 sequencing dataset that can be used to decipher the transcriptome of the planarian S. mediterranea, an organism that has great potential for the study of regeneration processes.
We obtained more than half a million sequencing reads and assembled them into different datasets using a number of different similarity thresholds. The complete dataset has been made publicly available via web [21]. About 50,000 contigs in one of those sets (90e) were mapped against the most up-to-date genome scaffolds and to the set of known proteins from NCBI NR. Interestingly, we found a large number of transcribed sequences not covered by the genome sequence (more than $3 \mathrm{Mbp}$ ). The novel 454 contigs will allow us to extend current genomic sequences and connect up to 8,000 pairs of genome scaffolds. Furthermore, a preliminary analysis of the planarian splice sites was made on a collection of 454 contigs mapped univocally to the genome. Annotation of the sequences yielded a number of gene candidates in different functional categories that will be useful for further experimental studies. However, 
a

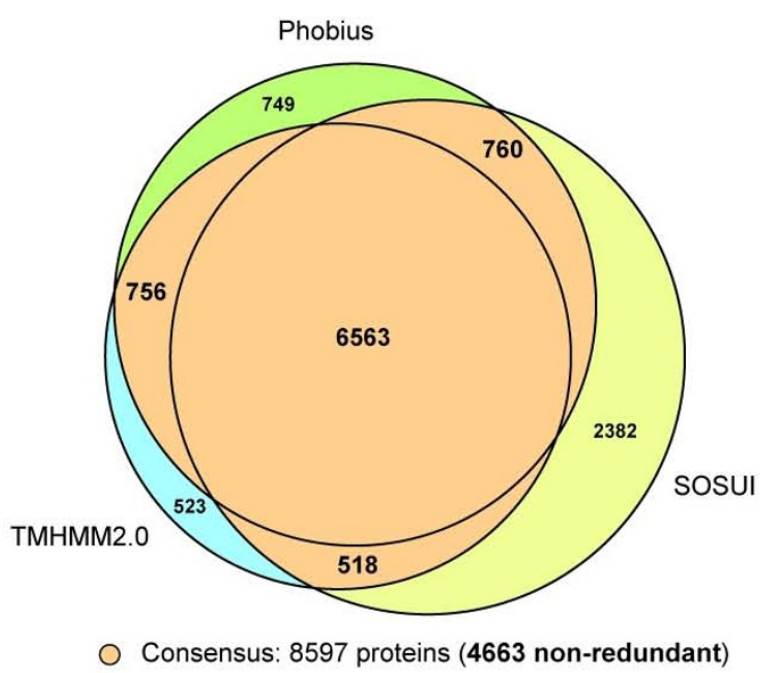

b

Top ten annotated Pfam domains
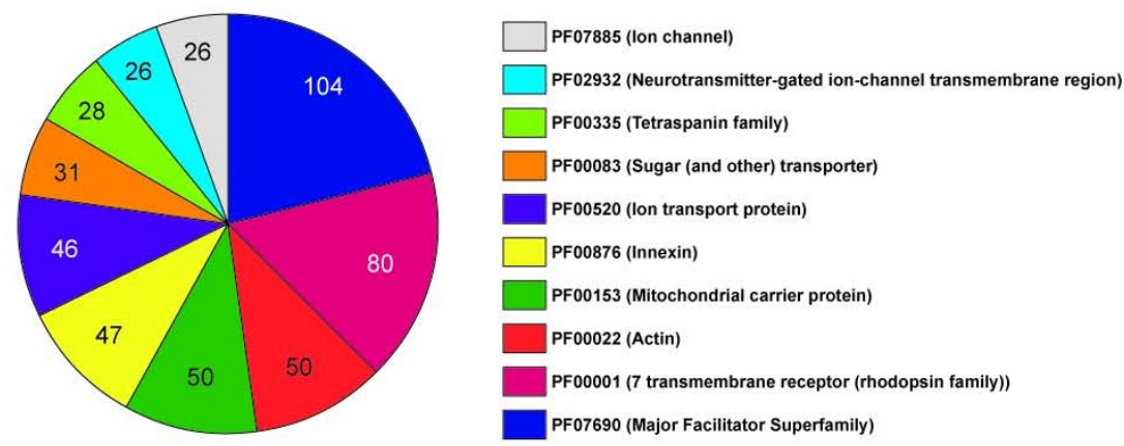

C

Top ten annotated gene ontology (biological process)
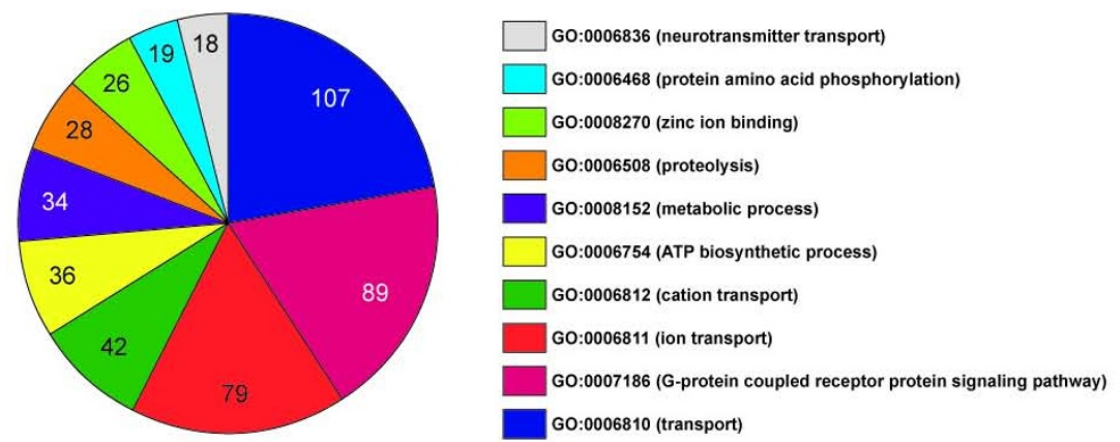

Figure 7 Prediction of planarian transmembrane proteins and functional annotations. A) Venn-diagram showing the overlap between predictions of transmembrane proteins generated by the Phobius, TMHMM2. 0 and SOSUI programs for a set of 56,362 protein sequences translated from planarian ESTs. Only proteins predicted to contain one or more transmembrane domains by at least two programs (colored orange, 8,597 proteins, of which 4,663 are non-redundant) were considered for further analysis. B) Top ten PFAM domains and C) gene ontologies (biological process) for the 4,663 non-redundant transmembrane-proteins predicted. The figures indicate the number of proteins contained in a given annotation group. 
Table 3 List of neurotransmitter, peptide and hormone receptor sequence candidates.

\begin{tabular}{|c|c|c|c|}
\hline ID & BLASTX HIT & ACCESSION NUMBER & E-VALUE \\
\hline $90 \_1623$ & adiponectin receptor (Schistosoma mansoni) & XP_002577010.1 & $2,00 \mathrm{E}-103$ \\
\hline 90_11706 & allatostatin receptor, putative (Ixodes scapularis) & XP_002414997.1 & $2,00 \mathrm{E}-18$ \\
\hline 90_9653 & amine GPCR (Schistosoma mansoni) & XP_002576533.1 & $8,00 \mathrm{E}-25$ \\
\hline P02IKPED & atrial natriuretic peptide receptor (Aedes aegypti) & XP_001652228.1 & $7,00 \mathrm{E}-28$ \\
\hline P02HWID8 & beta adrenergic receptor (Aedes aegypti) & XP_001651714.1 & $2,00 \mathrm{E}-18$ \\
\hline 90_17484 & similar to bombesin-like peptide receptor (Ornithorhynchus anatinus) & XP_001514235.1 & $2,00 \mathrm{E}-12$ \\
\hline 90_19322 & C1A receptor, putative (Ixodes scapularis) & XP_002405845.1 & $4,00 \mathrm{E}-04$ \\
\hline $90 \_4815$ & calcitonin receptor, isoform CRA_d (Rattus norvegicus) & AAA65964.1 & $3,00 \mathrm{E}-50$ \\
\hline 90_20672 & cardioexcitatory receptor (Lymnaea stagnalis) & AAB92258.1 & $6,00 \mathrm{E}-11$ \\
\hline $90 \_6224$ & class b secretin-like g-protein coupled receptor GPRmth5 (Pediculus humanus) & XP_002427184.1 & $2,00 \mathrm{E}-10$ \\
\hline P02IZJB4 & similar to putative diuretic hormone receptor II (Nasonia vitripennis) & XP_001606711.1 & $4,00 \mathrm{E}-22$ \\
\hline 90_7506 & type I dopamine receptor (Panulirus interruptus) & ABB87183.1 & $8,00 \mathrm{E}-69$ \\
\hline 90_6802 & dopamine receptor type D2 (Apis mellifera) & NP_001011567.1 & $2,00 \mathrm{E}-27$ \\
\hline 90_8536 & dro/myosuppressin receptor (Schistosoma mansoni) & XP_002570000.1 & $7,00 \mathrm{E}-26$ \\
\hline 90_9052 & FMRFamide receptor (Culex quinquefasciatus) & XP_001849293.1 & $2,00 \mathrm{E}-17$ \\
\hline P02GUXTP & similar to galanin receptor type I (Danio rerio) & XP_690480.1 & $3,00 \mathrm{E}-06$ \\
\hline $90 \_6830$ & glutamate receptor kainate (Schistosoma mansoni) & XP_002576035.1 & $3,00 \mathrm{E}-70$ \\
\hline P02GLFYW & glutamate receptor NMDA (Schistosoma mansoni) & XP_002572261.1 & $3,00 E-21$ \\
\hline 90_15092 & glutamate receptor, ionotropic, AMPA 1b (Danio rerio) & NP_991293.1 & $5,00 E-78$ \\
\hline 90_13524 & metabotropic glutamate receptor (Schistosoma mansoni) & XP_002572726.1 & $1,00 \mathrm{E}-12$ \\
\hline 90_18656 & gonadotropin-releasing hormone receptor type I (Capra hircus) & ABL76162.1 & 7,00E-04 \\
\hline $90 \_4098$ & growth hormone secretagogue receptor (Schistosoma mansoni) & XP_002569813.1 & $7,00 \mathrm{E}-36$ \\
\hline 90_976 & growth hormone-inducible transmembrane protein (Osmerus mordax) & AC008873.1 & $2,00 \mathrm{E}-51$ \\
\hline 90_6465 & putative insulin receptor (Echinococcus multilocularis) & CAD30260.1 & $6,00 \mathrm{E}-61$ \\
\hline 90_7253 & lung seven transmembrane receptor (Culex quinquefasciatus) & XP_001868443.1 & $1,00 \mathrm{E}-68$ \\
\hline 90_17047 & metabotropic GABA-B receptor subtype, putative (Ixodes scapularis) & XP_002406087.1 & $4,00 \mathrm{E}-21$ \\
\hline $90 \_6512$ & natriuretic peptide receptor (Xenopus laevis) & NP_001083703.1 & $4,00 \mathrm{E}-158$ \\
\hline 90_12800 & muscarinic acetylcholine (GAR) receptor (Schistosoma mansoni) & XP_002575679.1 & $2,00 \mathrm{E}-39$ \\
\hline 90_1507 & Nicotinic acetylcholine receptor alpha 1 subunit (Aplysia californica) & AF467898_1 & $3,00 \mathrm{E}-44$ \\
\hline 90_223 & neuroendocrine protein 7b2 (Schistosoma mansoni) & XP_002578500.1 & $6,00 \mathrm{E}-25$ \\
\hline $90 \_6302$ & similar to neuromedin U receptor 2 (Strongylocentrotus purpuratus) & XP_001200425.1 & $4,00 \mathrm{E}-27$ \\
\hline 90_29452 & neuropeptide FF receptor 2 isoform 3 (Homo sapiens) & NP_001138228.1 & 2,00E-09 \\
\hline $90 \_6772$ & neuropeptide F-like receptor (Schistosoma mansoni) & XP_002573542.1 & $1,00 \mathrm{E}-28$ \\
\hline 90_5995 & neuropeptide Y receptor Y7 (Oncorhynchus mykiss) & ABB54774.1 & $9,00 \mathrm{E}-18$ \\
\hline 90_25975 & octopamine receptor (Aplysia californica) & AAF37686.1 & $1,00 \mathrm{E}-25$ \\
\hline 90_8498 & odorant receptor (Tetraodon nigroviridis) & CAG08888.1 & $6,00 \mathrm{E}-05$ \\
\hline 90_5999 & similar to olfactory receptor 355 (Bos taurus) & XP_610381.4 & $1,00 \mathrm{E}-05$ \\
\hline 90_2541 & P2Y purinergic receptor (Meleagris gallopavo) & AAA18784.1 & 2,00E-04 \\
\hline 90_8537 & P2X receptor subunit (Schistosoma mansoni) & XP_002580774.1 & $1,00 \mathrm{E}-72$ \\
\hline 90_19040 & pituitary adenylate cyclase activating polypeptide receptor (Oncorhynchus mykiss) & NP_001118113.1 & $1,00 \mathrm{E}-08$ \\
\hline 90_28219 & parathyroid hormone 2 receptor (Danio rerio) & AAl62580.1 & $3,00 \mathrm{E}-11$ \\
\hline $90 \_6836$ & peptide (allatostatin)-like receptor (Schistosoma mansoni) & XP_002572656.1 & $2,00 \mathrm{E}-66$ \\
\hline 90_7984 & peptide (allatostatin/somatostatin)-like receptor (Schistosoma mansoni) & XP_002575539.1 & $2,00 \mathrm{E}-32$ \\
\hline 90_10769 & progesterone receptor membrane component 1 (Danio rerio) & NP_001007393.1 & 7,00E-04 \\
\hline $90 \_5450$ & progestin receptor membrane component 1 (Oryzias latines) & BAE47967.1 & $2,00 \mathrm{E}-28$ \\
\hline P02GZGVI & prolactin releasing hormone receptor (Homo sapiens) & BAG36078.1 & 2,00E-06 \\
\hline P02I1U9K & pyrokinin-like receptor (Dermacentor variabilis) & ACC99623.1 & $2,00 \mathrm{E}-11$ \\
\hline 90_10680 & Rhodopsin-like GPCR superfamily, domain-containing protein (Schistosoma japonicum) & CAX73015.1 & $6,00 \mathrm{E}-37$ \\
\hline 90_2955 & rhodopsin-like orphan GPCR (Schistosoma mansoni) & XP_002579928.1 & $2,00 \mathrm{E}-42$ \\
\hline 90_27829 & ryanodine receptor 44F (Schistosoma japonicum) & CAX69439.1 & $8,00 \mathrm{E}-16$ \\
\hline 90_14326 & serotonin receptor-like planarian receptor 1 (Dugesia japonica) & BAA22404.1 & $3,00 \mathrm{E}-54$ \\
\hline
\end{tabular}


Table 3 List of neurotransmitter, peptide and hormone receptor sequence candidates. (Continued)

\begin{tabular}{|c|c|c|c|}
\hline 90_15981 & serotonin receptor 7 (Dugesia japonica) & BAI44327.1 & $2,00 \mathrm{E}-14$ \\
\hline 90_11349 & sex peptide receptor (Tribolium castaneum) & NP_001106940.1 & $5,00 \mathrm{E}-25$ \\
\hline P02HBR62 & SIFamide receptor (Apis mellifera) & NP_001106756.1 & $9,00 \mathrm{E}-10$ \\
\hline 90_19415 & parathyroid hormone-related peptide receptor precursor (Tribolium castaneum) & XP_969953.1 & $7,00 E-20$ \\
\hline P02FKOY5 & parathyroid hormone receptor 2, isoform CRA_c (Mus musculus) & EDL00229.1 & $3,00 \mathrm{E}-07$ \\
\hline 90_1140 & somatostatin receptor (Culex quinquefasciatus) & XP_001859671.1 & $7,00 E-43$ \\
\hline P02JZNDR & tachykinin receptor 1 (Mus musculus) & NP_033339.2 & $2,00 \mathrm{E}-06$ \\
\hline P02FL51R & thyroid hormone receptor (Schistosoma mansoni) & XP_002573733.1 & $2,00 E-23$ \\
\hline P02FHDMB & thyroid stimulating hormone receptor precursor (Canis lupus familiares) & NP_001003285.1 & $5,00 \mathrm{E}-04$ \\
\hline 90_3545 & thyrotropin-releasing hormone receptor 1 (Catostomus commersonii) & AAG31763.1 & $2,00 E-51$ \\
\hline 90_26294 & tyramine receptor (Bombyx mori) & BAD11157.1 & $1,00 \mathrm{E}-11$ \\
\hline
\end{tabular}

many of the novel contigs have no similarity to known proteins and will require further validation if we want to understand the transcriptional inventory of the planarian at a functional level. We also provided a preliminary gene annotation for $S$. mediterranea, focusing our rankings on four different gene families; these serve as applied examples of the usefulness of this new sequence resource.

\section{Methods}

\section{Animals and RNA isolation}

Schmidtea mediterranea from the BCN-10 clonal line were used. Animals were starved one week prior to experiments and irradiated at a lethal dose of 100Gy. Total RNA was isolated from a mixed sample of planarians that contained non-irradiated intact and regenerating planarians (1, 3, 5 and 7 days of regeneration) as well as irradiated intact and regenerating animals $(1,3$, 5 and 7 days of regeneration). RNA was extracted with TRIzol $^{\odot}$ (Invitrogen) following the manufacturer's instructions.

\section{cDNA library construction and $\mathbf{4 5 4}$ sequencing}

First, $5 \mu \mathrm{g}$ of total RNA was used to construct a cDNA library. RNA quality was assessed in a Bioanalyzer 2100 (Agilent-Bonsai Technologies). $5 \mu \mathrm{g}$ of full-length doublestranded cDNA was then processed by the standard Genome Sequencer library-preparation method using the 454 DNA Library Preparation Kit (Titanium chemistry) to generate single-stranded DNA ready for emulsion PCR $\left(\mathrm{emPCR}^{\mathrm{Ts}}\right)$. The $\mathrm{cDNA}$ library was then nebulized according to the fragmentation process used in the standard Genome Sequencer shotgun library preparation procedure. The cDNA library was sequenced according to GS FLX technology (454/Roche). Reads were assembled by MIRA[60] version 3 using enhanced 454 parameters.

\section{Mapping to genomic and functional annotation}

BLAT[61] was used with default parameters to map the Smed454 90e dataset on the $S$. mediterranea draft genome assembly v3.1 [14] since the 454 sequences should be very similar to the corresponding genomic sequences, except for the lack of introns. Perl scripts were developed to classify all HSPs into the categories shown in Figure 3. 90e contigs having two or more collinear HSPs covering more than 100bp of the contig, and for which HSPs had more than $90 \%$ identity to the genomic contigs and length of the HSP larger than $50 \mathrm{bp}$, were chosen as 1-to- 1 matches to genome. Once the sequences of the 90e/genomic contig pairs were retrieved, exonerate[62] was used to refine the alignments over the splice sites (using as parameters model = est 2 genome and bestn $=10$ ). Perl scripts were used to retrieve the splice sites coordinates from exonerate output, as well as the sequences from genomic contigs. After clipping the donor and acceptor splice sites for each intron, nucleotide frequencies were computed and the corresponding position weight matrices for U2/U12 sites were drawn as pictograms using compi[19]. Known S. mediterranea genes were compared with contigs from 90e using BLASTN[63] with the following cut-offs: evalue $=0.001$, identity score $>80 \%$, HSP length $>50 \mathrm{bp}$.

GO functional annotation was computed on the BLASTX[63] results of the three assembly datasets (90, 98, and 90e) against all proteins from NCBI NR. BLASTX parameters were set to e-value $=10 \mathrm{e}-25$ and maximum number of descriptions and alignments to report $=250$, which produced around 26 million HSPs for each set. After that, only HSPs with a minimum length of $80 \mathrm{bp}$ and a similarity score of at least $80 \%$ were considered. GO annotation was performed on those HSPs using the e-value selection criteria and supporting sequences described for Blast2 $\mathrm{GO}[64]$. Further Perl scripts were used to summarize the data shown in Table 2 and Additional File 3.

\section{RT-PCR}

In order to validate the expression of a random subset of novel 454 transcripts, RT-PCRs were performed on planarian cDNA generated with Superscript III (Invitrogen) following the manufacturer's instructions. Additional File 
Table 4 Complete list of homeobox-containing gene sequence candidates.

\begin{tabular}{|c|c|c|c|}
\hline ID & BLASTX HIT & ACCESSION NUMBER & E-VALUE \\
\hline F6AJIXP02J3PG4 & arrowhead [Schistosoma mansoni] & XP_002575389 & $6,00 \mathrm{E}-09$ \\
\hline 90_9219 & barh homeobox protein [Schistosoma mansoni] & XP_002571667 & $9,00 \mathrm{E}-26$ \\
\hline F6AJIXP02J2YIH & brain-specific homeobox [Tribolium castaneum] & EFA05724 & $5,00 \mathrm{E}-05$ \\
\hline 90_23337 & cut, isoform C [Drosophila melanogaster] & NP_001138174 & $3,00 \mathrm{E}-18$ \\
\hline F6AJIXP02HF7ZO & cut, isoform C [Drosophila melanogaster] & NP_001138174 & $2,00 \mathrm{E}-10$ \\
\hline $90 \_8368$ & Cut-like homeobox 1 [Mus musculus] & AAH14289 & $2,00 \mathrm{E}-23$ \\
\hline 90_3019 & distalless, Dlx-1 [Platynereis dumerilii] & CAJ38799 & $8,00 \mathrm{E}-07$ \\
\hline 90_14605 & DjotxB [Dugesia japonica] & BAF80446 & $4,00 \mathrm{E}-65$ \\
\hline F6AJIXP02FICZL & Eye absent protein [Dugesia japonica] & CAD89530 & $1,00 \mathrm{E}-74$ \\
\hline F6AJIXP02IV6Y0 & gsx family homeobox protein [Schistosoma mansoni] & XP_002574396 & $3,00 \mathrm{E}-12$ \\
\hline 90_24312 & H6-like-homeobox [Drosophila melanogaster] & NP_732244 & $2,00 \mathrm{E}-15$ \\
\hline 90_8293 & homeobox protein distal-less dlx [Schistosoma mansoni] & XP_002574393 & $4,00 \mathrm{E}-07$ \\
\hline F6AJIXP02JJ1QK & Homeobox protein DTH-2 [Girardia tigrina] & Q00401 & $3,00 \mathrm{E}-40$ \\
\hline 90_8753 & homeobox prox 1 [Danio rerio] & NP_956564 & $5,00 \mathrm{E}-19$ \\
\hline 90_12057 & homeodomain protein Tlx [Capitella teleta] & ACH89436 & $1,00 \mathrm{E}-23$ \\
\hline 90_8083 & Hox class homeodomain protein AbdBa Hox protein [Schmidtea mediterranea]. & ABW79872 & $1,00 \mathrm{E}-26$ \\
\hline 90_7618 & Hox class homeodomain protein DjAbd-Ba [Dugesia japonica] & BAB41079 & $2,00 \mathrm{E}-16$ \\
\hline 90_6369 & Hox class homeodomain protein DjAbd-Bb [Dugesia japonica] & BAB41078 & $1,00 \mathrm{E}-108$ \\
\hline F6AJIXP02ILMDY & Hox class homeodomain protein DjAbd-Bb [Dugesia japonica] & BAB41078 & $3,00 \mathrm{E}-33$ \\
\hline F6AJIXP02HN15J_2 & Hypothetical protein CBG18604 [Caenorhabditis briggsae] & XP_002638395 & $7,00 \mathrm{E}-05$ \\
\hline 90_28860 & ladybird homeobox corepressor 1-like protein [Mus musculus & NP_001103213 XP_001479028 & $8,00 \mathrm{E}-33$ \\
\hline 90_6629 & lim domain binding protein [Schistosoma mansoni] & XP_002576324 & $6,00 \mathrm{E}-05$ \\
\hline F6AJIXP02GEYYP & lim domain homeobox 3/4 transcription factor [Saccoglossus kowalevskii) & NP_001158395 & $4,00 \mathrm{E}-23$ \\
\hline 90_10783 & lim homeobox protein [Schistosoma mansoni] & XP_002579046 & $2,00 \mathrm{E}-13$ \\
\hline 90_11027 & lim homeobox protein [Schistosoma mansoni] & XP_002579046 & $1,00 \mathrm{E}-26$ \\
\hline 90_10828 & LIM homeobox transcription factor 1 alpha [Mus musculus] & EDL39177 & $2,00 \mathrm{E}-14$ \\
\hline 90_13775 & LIM motif-containing protein kinase 1 [Schistosoma japonicum] & CAX72746 & $2,00 \mathrm{E}-11$ \\
\hline 90_9432 & LIM-homeodomain protein AmphiLim1/5 [Branchiostoma floridae] & ABD59002 & $5,00 \mathrm{E}-05$ \\
\hline 90_8762 & LIM-homeodomain transcription factor islet [Branchiostoma floridae & AAF34717 & $2,00 \mathrm{E}-15$ \\
\hline 90_6339 & Nk1 protein [Platynereis dumerilii] & CAJ38797 & $1,00 \mathrm{E}-11$ \\
\hline F6AJIXP02G077U & paired-like homeobox 2a [Danio rerio] & NP_996953 & $5,00 \mathrm{E}-16$ \\
\hline 90_6703 & phtf [Drosophila melanogaster] & NP_610232 & $2,00 \mathrm{E}-55$ \\
\hline 90_25126 & PLOX2-Dj [Dugesia japonica] & BAA77402 & $2,00 \mathrm{E}-42$ \\
\hline $90 \_21567$ & PLOX4-Dj [Dugesia japonica] & BAA77404 & $2,00 \mathrm{E}-21$ \\
\hline 90_23010 & PLOX5-Dj [Dugesia japonica] & BAA77405 & $6,00 \mathrm{E}-22$ \\
\hline F6AJIXP02IVOTI & PLOX5-Dj [Dugesia japonica] & BAA77405 & $1,00 \mathrm{E}-17$ \\
\hline 90_21710 & pre-B-cell leukemia transcription factor 1234 (pbx) [Schistosoma mansoni) & XP_002572195 & $2,00 \mathrm{E}-27$ \\
\hline 90_3405 & PREDICTED: similar to UBX domain protein 4 [Hydra magnipapillata] & XP_002162754 & $2,00 \mathrm{E}-06$ \\
\hline F6AJIXP02HI24E & PREP homeodomain-like protein [Schmidtea mediterranea] & ADB54565 & $2,00 \mathrm{E}-47$ \\
\hline F6AJIXP02JSRJD & PREP homeodomain-like protein [Schmidtea mediterranea] & ADB54565 & $1,00 \mathrm{E}-32$ \\
\hline F6AJIXP02GVFDM & prospero-like protein [Schistosoma mansoni] & XP_002578694 & $1,00 \mathrm{E}-21$ \\
\hline F6AJIXP02IUJ5Q & prospero-like protein [Schistosoma mansoni] & XP_002578694 & $4,00 \mathrm{E}-25$ \\
\hline F6AJIXP02HZIDG & short stature homeobox protein 2 isoform c [Homo sapiens & NP_001157150 & $5,00 \mathrm{E}-08$ \\
\hline 90_7545 & SIX homeobox 2 [Gallus gallus] & NP_001038160 & $7,00 \mathrm{E}-36$ \\
\hline F6AJIXP02HBGHT & SJCHGC06100 protein [Schistosoma japonicum] & AAW24487 & $6,00 \mathrm{E}-11$ \\
\hline 90_3395 & UBX domain containing 8, isoform CRA_d [Mus musculus] & EDL41153 & $3,00 \mathrm{E}-14$ \\
\hline $90 \_1176$ & UBX domain-containing protein 4 [Mus musculus] & NP_080666 & $1,00 \mathrm{E}-06$ \\
\hline $90 \_2625$ & ubx6(yeast)-related [Schistosoma mansoni] & XP_002576054 & $2,00 \mathrm{E}-16$ \\
\hline 90_24438 & visual system homeobox protein [Tribolium castaneum] & CAX64460 & $9,00 \mathrm{E}-23$ \\
\hline F6AJIXP02G5JJX_1 & Zn finger homeodomain 2 [Tribolium castaneum] & EFA01350 & $1,00 \mathrm{E}-05$ \\
\hline
\end{tabular}


Table 5 List of eye-related gene sequence candidates.

\begin{tabular}{|c|c|c|c|}
\hline ID & BLASTX HIT & ACCESSION Nr. & E-VALUE \\
\hline 90_7233 & abl interactor 2 [Schistosoma japonicum] & CAX69750.1 & 6.00E-019 \\
\hline 90_4001 & adaptor-related protein complex [Schistosoma mansoni] & XP_002574891.1 & $3.00 \mathrm{E}-072$ \\
\hline 90_30923 & arginine/serine-rich splicing factor [Schistosoma mansoni] & XP_002574990.1 & 2.00E-026 \\
\hline 90_482 & ATPase protein [Schistosoma japonicum] & AAW26203.1 & 3.00E-049 \\
\hline 90_3152 & beta-catenin-like protein 2 [Schmidtea mediterranea] & ABW79874.1 & 0 \\
\hline 90_12909 & BMP [Schmidtea mediterranea] & ABV04322.1 & 3.00E-090 \\
\hline 90_120 & cat eye syndrome protein [Schistosoma japonicum] & AAX27345.2 & 4.00E-035 \\
\hline P02FKNEB & CaTaLase family member (ctl-2) [Caenorhabditis elegans] & NP_001022473.1 & 1.00E-029 \\
\hline 90_205 & Chaperonin Containing TCP-1 family member (cct-3) [Caenorhabditis elegans] & NP_494218.2 & 1.00E-090 \\
\hline C90_6158 & disks large homolog 1 isoform 1 [Homo sapiens] & NP_001091894.1 & 2.00E-027 \\
\hline P02GJNCV & extradenticle 1 protein [Schistosoma japonicum] & AAW24487.1 & 3.00E-013 \\
\hline P02JKJ4Z_2 & eye53 [Dugesia japonica] & BAD20650.1 & $6.00 \mathrm{E}-016$ \\
\hline 90_8483 & eyes absent protein [Dugesia japonica] & CAD89531.1 & 2.00E-064 \\
\hline 90_651f & ascin protein [Schistosoma japonicum] & XP_002574990.1 & 5.00E-045 \\
\hline 90_14368 & heat shock protein 70 [Lumbricus terrestris] & ACB77918.1 & 4.00E-038 \\
\hline 90_9533 & Heparan sulfate 6-O-sulfotransferase 2 [Danio rerio] & AAH45453.1 & 1.00E-042 \\
\hline $90 \_6564$ & histone-lysine n-methyltransferase suv9 [Schistosoma mansoni] & XP_002574171.1 & 3.00E-061 \\
\hline 90_15456 & homeodomain protein NK4 [Platynereis dumerilii] & ABQ10640.1 & $8.00 \mathrm{E}-023$ \\
\hline 90_12892 & homeotic protein six3-alpha [Mus musculus] & S74256 & 1.00E-082 \\
\hline 90_325 & importin-7 [Culex quinquefasciatus] & XP_001843364.1 & 2.00E-147 \\
\hline $90 \_4360$ & intraflagellar transport 57 homolog [Xenopus (Silurana) tropicalis] & NP_001016561.1 & 1.00E-044 \\
\hline 90_11027 & lim homeobox protein [Schistosoma mansoni] & XP_002579046.1 & $5.00 \mathrm{E}-027$ \\
\hline 90_8432 & lozenge [Schistosoma mansoni] & XP_002580418.1 & 8.00E-032 \\
\hline 90_8924 & Male ABnormal family member (mab-21) [Caenorhabditis elegans] & NP_497940.2 & 1.00E-046 \\
\hline P02HSHWR & mothers against decapentaplegic homolog 4 [Mus musculus] & NP_032566.2 & 5.00E-018 \\
\hline 90_5640 & muscleblind-like protein [Schistosoma mansoni] & XP_002575346.1 & $3.00 \mathrm{E}-025$ \\
\hline P02F0EF6 & neurogenic differentiation [Platynereis dumerilii] & CAQ57533.1 & 2.00E-012 \\
\hline P02GMLJM & nuclear transcription factor X-box binding 1 ( $\mathrm{nf} \times 1)$ [Schistosoma bovis] & XP_002577564.1 & $5.00 \mathrm{E}-014$ \\
\hline 90_828 & phenylalanine hydroxylase [Caenorhabditis elegans] & AAD31643.1 & 2.00E-145 \\
\hline 90_2925 & protein [Schistosoma japonicum] & AAW24487.1 & $4.00 \mathrm{E}-126$ \\
\hline 90_7228 & protein kinase [Schistosoma mansoni] & XP_002576342.1 & 2.00E-077 \\
\hline 90_2256 & Protein pob [Schistosoma japonicum] & CAX75988.1 & 4.00E-089 \\
\hline 90_4436 & Rab-protein 6 [Drosophila melanogaster] & NP_477172.1 & 8.00E-085 \\
\hline P02GENUT_1 & retinaldehyde dehydrogenase 1 [Eleutherodactylus coqui] & ACE74542.1 & 8.00E-008 \\
\hline 90_11988 & runt protein [Branchiostoma lanceolatum] & AAN08565.1 & 4.00E-017 \\
\hline P02FN7BT & Septin-7 (CDC10 protein homolog) [Schistosoma japonicum] & CAX83064.1 & 3.00E-012 \\
\hline 90_3747 & serine/threonine protein kinase [Schistosoma mansoni] & XP_002580180.1 & 9.00E-094 \\
\hline P02FICZL & six1-2 protein [Dugesia japonica] & CAD89530.1 & 8.00E-86 \\
\hline P02IZDJZ_1 & SRY-related HMG box B protein [Platynereis dumerilii] & CAY12631.1 & $3.00 \mathrm{E}-028$ \\
\hline P02HE4J6 & strabismus protein CBR-VANG-1 [Platynereis dumerilii] & CAJ26300.1 & $1.00 \mathrm{E}-006$ \\
\hline 90_9483 & tetratricopeptide repeat protein 10 tpr10 [Schistosoma mansoni] & XP_002573898.1 & 4.00E-048 \\
\hline 90_16088 & tyrosine kinase [Schistosoma mansoni] & XP_002576978.1 & 2.00E-031 \\
\hline 90_11388 & ubiquitin conjugating enzyme E2 [Schistosoma mansoni] & XP_002578016.1 & 3.00E-053 \\
\hline $90 \_1263$ & vacuolar ATP synthase proteolipid subunit 123 [Schistosoma japonicum] & XP_002571892.1 & 9.00E-049 \\
\hline 90_12567 & vermilion [Drosophila ananassae] & XP_001963597.1 & 2.00E-012 \\
\hline 90_5500 & white pigment protein [Drosophila melanogaster] & CAA26716.2 & 2.00E-020 \\
\hline 90_13309 & YY1 transcription factor [Schistosoma japonicum] & CAX73893.1 & 5.00E-049 \\
\hline 90_10118 & zinc finger protein 42 homolog [Homo sapiens] & NP_777560.2 & $6.00 \mathrm{E}-031$ \\
\hline 90_9460 & 14-3-3 zeta isoform [Schistosoma bovis] & AAT39382.1 & $2.00 \mathrm{E}-023$ \\
\hline P02ILIK3 & 52-kD bracketing protein [Drosophila melanogaster] & CAA44483.1 & 1.00E-016 \\
\hline
\end{tabular}


3 includes a list of the contigs validated and the primers used for each of them.

\section{Prediction of transmembrane proteins from ESTs}

A total of 53,867 assembled ESTs (90e database) and 2,495 additional mRNAs were translated into all six reading frames using the 'transeq' program from the EMBOSS package [65]. The longest open reading frame for each $\mathrm{EST} / \mathrm{mRNA}$ was then extracted and used as a protein database (containing 56,362 protein sequences overall) for the prediction of membrane-spanning proteins. We followed an approach described by Almen et al. [66] basing our analysis on consensus predictions of alpha-helices and using three applications: Phobius[67], TMHMM2 . o [68], and SOSUI[69]. Phobius and TMHMM2 . 0 both use hidden Markov models based on different training sets to predict membrane topology. SOSUI evaluates proteins for their hydrophobic and amphiphilic properties to make its predictions. The use of all three programs should improve prediction accuracy. We first ran Phobius, which can predict both transmembrane helices and signal peptides. Signal peptide sequences are similar to transmembrane segments owing to their hydrophobic nature [70]. To avoid false positive predictions, we excluded signal peptides before running TMHMM2 .0 and SOSUI.

\section{Additional material}

Additional file 1: GO annotation for 90 e contigs not mapping onto the WUSL 3.1 genome assembly. 8,831 90e contigs were not found in the genome. 3,480 had a BLASTX hit to a sequence of NCBI NRprot; yet only 2,401 had a hit to a protein functionally annotated in the GO database. This file contains the description of the best HSP for 71 of those annotated contigs, after filtering out as described above. (Header: CONTIG ID = Smed454 sequence identifier, E-VALUE = BLASTX HSP Evalue, $A L N \_S C O R E=H S P$ alignment score, IDENTITIES $=$ number of identical amino acids, POSITIVES = number of similar amino acids, SEQUENCE ID = Protein sequence identifier, ACCESSION NUMBER = Protein sequence full accession number, SEQUENCE DESCRIPTION = Full protein GenBank description).

Additional file 2: Splice sites for a subset of Smed454 sequences mapped onto the Schmidtea mediterranea genome. (Header: GID = Genomic contig IDentifier from WUSLV3.1 genome assembly-including the start and end nucleotide coordinates for the complete match-, $\mathrm{CIG}=\mathbf{9 0 e}$ contig IDentifier, INTNUM = Intron number within the $\mathbf{9 0 e}$ contig, $\mathrm{EXO}=$ splice signals found by exonerate, $\mathrm{ORI}=$ sequence orientation-here -1 means that the match was found on the reverse strand of the genomic contig-, CEXO = corrected splice site signals after reverse complementing the genomic sequence when required, ILEN = Intron length in bp, IORI = Intron start-relative to the match coordinates-, IEND = Intron end-relative to the match coordinates-, STRAND, SSSEQ = Splice sites sequences-where a point separates three nucleotides from the $5^{\prime}$ and $3^{\prime}$ exons, and the three dots in the middle denote intron sequence not shown for clarity-).

Additional file 3: List of $90 \mathrm{e}$ transcripts validated by RT-PCR. (Header: \# = Number, CONTIG=90e contig ID, PRIMER_FORWARD $=5^{\prime}$ to $3^{\prime}$ sequence of the forward primer used, REVERSE_FORWARD $=5^{\prime}$ to $3^{\prime}$ sequence of the reverse primer used, AMPLICON SIZE = Size amplified in $\mathrm{bp}, \mathrm{SET}=$ refers to the subset of origin of the $\mathbf{9 0 e}$ contig: no hit genome, hit genome, - blast (no BLASTx hit), +blast (BLASTX hit)).
Additional file 4: Smed454 sequences matching known Schmidtea mediterranea genes. (Header: ACCESSION NUMBER = Known gene sequence identifier as target, NAME = Description for that sequence, LENGTH $=$ Nucleotide length for that sequence, A\&T CONTENT = Sequence composition, 454 90e CONTIG/SINGLETON = Smed454 sequence identifier as query, LENGTH = Nucleotide sequence length for this sequence, ALIGNMENT LENGTH $=$ HSP length, START $=$ Start nucleotide of alignment on target, END = Final nucleotide of alignment on target, IDENTITY = Identity score, BITSCORE = Alignment bit score, EVALUE = HSP BLAST e-value, HIT LENGTH = Un-gapped length of the alignment on the target, \%COVERAGE = Sum of co-linear HSPs on target coordinates divided by the total length of the target, \#SEQs = Number of co-linear HSPs considered, avg\%COV = The coverage divided by the number of co-linear HSPS).

Additional file 5: Gene Ontology for all three Smed454 sets: 90, 98 and $90 \mathrm{e}$. Level one and two GO codes are shown in order to simplify the listings. Although there are small changes in $\mathrm{GO}$ frequencies, annotation is consistent throughout all three sets. (Header: $\mathrm{GO}=\mathrm{Gene}$ Ontology unique identifier, Count $=$ Number of sequences with a given $\mathrm{GO}$ annotation, Freq\% = Frequencies for every GO annotation. The total shown does not include the un-annotated and over-represented features, that is, the first two rows on each table).

Additional file 6: List of cell cycle, cell division, DNA repair or DNA damage candidates. Short list of candidates annotated as genes involved in cell cycle, cell division, DNA repair or DNA damage. (Header: ID = Smed454 sequence identifier, BLASTX HIT = Description of the best sequence hit, ACCESSION NUMBER = Sequence identifier of the best sequence hit, E-VALUE = BLASTX e-value for that sequence hit).

Additional file 7: Summary report for the consensus set of 4,663 predicted transmembrane proteins including functional annotations. (Header: Sequence_ID = Protein sequence identifier, Sequence_AA = Amino acid sequence, Length[aa] = Length of amino acid sequence, Phobius_TM = Phobius prediction of number of transmembrane domains, Phobius_SP = Phobius prediction of signal peptide, Phobius_Top $=$ Phobius prediction of membrane topology, TMHMM_TM $=$ TMHMM2 .0 prediction of number of transmembrane domains, TMHMM_Top $=$ TMHMMv2 .0 prediction of membrane topology, SOSUI_TM = SOSUI prediction of number of transmembrane domains, SOSUI_Top = SOSUI prediction of membrane topology, UFO_PFAM = UFO annotation of Pfam protein families, UFO_GO = UFO annotation of gene ontologies).

Additional file 8: List of neurotransmitter, peptide and hormone receptor sequence candidates. Complete complement of Smed454 dataset contigs and singletons showing homology to neurotransmitter and hormone receptors, totalling 287 sequences. (Header: ID = Smed454 sequence identifier, BLASTX HIT = Description of the best sequence hit, ACCESSION NUMBER = Sequence identifier of the best sequence hit, EVALUE $=$ BLASTX e-value for that sequence hit).

Additional file 9: List of eye-related gene sequence candidates Complete complement of Smed454 dataset contigs and singletons showing homology to eye-related genes, totalling 95 sequences. (Header: ID = Smed454 sequence identifier, BLASTX HIT = Description of the best sequence hit, ACCESSION NUMBER = Sequence identifier of the best sequence hit, E-VALUE $=$ BLASTX e-value for that sequence hit).

\section{Abbreviations}

bp: base pairs (nucleotide length unit); EST: Expressed Sequence Tag; GC\%: percent of guanine+cytosine sequence content; HSP: High-scoring Segment Pair; GO: Gene Ontology; WUSL: Washington University in St Louis; TM: transmembrane; RDGN: retinal determination gene network; Gy: gray.

\section{Acknowledgements}

Genomic sequence data was produced by the Washington University Genome Sequencing Center in St. Louis. DNA library construction, 454 pyrosequencing and the contig browser were generated by Skuldtech (Montpellier, France). We thank Ann King for language revision and editorial advice, and Franziska Konert for technical assistance. SF and GRE are 
supported by FPI fellowships, and BC is supported by an FPU fellowship (both MICINN, Spain). TH is supported by a fellowship of the Studienstiftung des deutschen Volkes. FC is a Ramón y Cajal researcher (MICINN, Spain). This work was funded by grants BFU2008-01544 (MICINN) to ES, BFU2008-00710 (MICINN) to FC, BFU2009-09102(MICINN) to JFA, and 2009SGR1018 (AGAUR) to ES and FC. Finally, K.B. was funded by a FRONTIER grant from the University of Heidelberg DFG Excellence Initiative.

\section{Author details}

'Departament de Genètica, Facultat de Biología, Universitat de Barcelona (UB), Av. Diagonal 645, edifici annex, planta 1, 08028, Barcelona, Catalunya, Spain. ${ }^{2}$ Institut de Biomedicina de la Universitat de Barcelona (IBUB), Av. Diagonal 645, edifici annex, planta 1, 08028, Barcelona, Catalunya, Spain. ${ }^{3}$ Division of Signaling and Functional Genomics German Cancer Research Center (DKFZ), Im Neuenheimer Feld 580, 69120 Heidelberg, Germany. ${ }^{4}$ Max Planck Research Group Stem Cells and Regeneration Max-Planck-Institute for Molecular Biomedicine, Von-Esmarch-Strasse 54, 48149 Muenster, Germany.

\section{Authors' contributions}

JFA performed the computational analyses on the assemblies, the GO characterization, the mapping into the genome and the analysis of spliced sites, and prepared all the corresponding figures and tables. GRE analyzed the coverage of known annotated genes and generated the corresponding table. TH performed the sequence analysis of planarian transmembrane proteins, generated the corresponding figure and table and designed primers for RT-PCRs. GRE, SF, FC and KB designed the primers and performed the RT-PCRs. FC and SF analyzed the annotated data to characterize the neurotransmitter, peptide and hormone receptors and prepared the corresponding tables. ES and BC analyzed the annotated data to characterize homeobox-containing and eye-related genes and prepared the corresponding tables. JFA, KB, FC and ES conceived of the study, participated in its design and coordination, and helped draft the manuscript. All authors read and approved the final manuscript.

Received: 31 August 2010 Accepted: 31 December 2010 Published: 31 December 2010

\section{References}

1. Agata K, Tanaka T, Kobayashi C, Kato K, Saitoh Y: Intercalary regeneration in planarians. Dev Dyn 2003, 226(2):308-316.

2. Newmark PA, Sánchez Alvarado A: Not your father's planarian: a classic model enters the era of functional genomics. Nat Rev Genet 2002, 3(3):210-219.

3. Reddien PW, Sánchez-Alvarado A: Fundamentals of planarian regeneration. Annu Rev Cell Dev Biol 2004, 20:725-757.

4. Saló E: The power of regeneration and the stem-cell kingdom: freshwater planarians (Platyhelminthes). Bioessays 2006, 28(5):546-559.

5. Baguñà J, Saló E, Auladell C: Regeneration and pattern formation in planarians. III. Evidence that neoblasts are totipotent stem cells and the source of blastema cells. Development 1989, 107:77-86.

6. Newmark PA, Sánchez-Alvarado A: Bromodeoxyuridine specifically labels the regenerative stem cells of planarians. Dev Biol 2000, 220(2):142-153.

7. Cebrià F: Regenerating the central nervous system: how easy for planarians! Dev Genes Evol 2007, 217(11-12):733-748.

8. Scimone ML, Meisel J, Reddien PW: The Mi-2-like Smed-CHD4 gene is required for stem cell differentiation in the planarian Schmidtea mediterranea. Development 2010, 137(8):1231-1241.

9. Fernández-Taboada E, Moritz S, Zeuschner D, Stehling M, Scholer HR, Saló E, Gentile L: Smed-SmB, a member of the LSm protein superfamily, is essential for chromatoid body organization and planarian stem cell proliferation. Development 2010, 137(7):1055-1065.

10. Forsthoefel DJ, Newmark PA: Emerging patterns in planarian regeneration. Curr Opin Genet Dev 2009, 19(4):412-420.

11. Sánchez-Alvarado A, Newmark PA, Robb SM, Juste R: The Schmidtea mediterranea database as a molecular resource for studying platyhelminthes, stem cells and regeneration. Development 2002, 129(24):5659-5665.

12. Zayas RM, Hernandez A, Habermann B, Wang Y, Stary JM, Newmark PA: The planarian Schmidtea mediterranea as a model for epigenetic germ cell specification: analysis of ESTs from the hermaphroditic strain. Proc Natl Acad Sci USA 2005, 102(51):18491-18496.
13. Pontius JU, Wagner L, Schuler GD: UniGene: a unified view of the transcriptome. In The NCBI Handbook Edited by: Information NCfB. Bethesda (MD) 2003.

14. Schmidtea mediterranea genome sequencing project. [http://genome. wustl.edu/genomes/view/schmidtea_mediterranea/].

15. Proposal for the Sequencing of a New Target Genome: White Paper for a Planarian Genome Project. [http://genome.wustl.edu/images/uploads/ Whitepaper/Schmidtea_mediterranea_WP.pdf].

16. Cantarel BL, Korf I, Robb SM, Parra G, Ross E, Moore B, Holt C, SánchezAlvarado A, Yandell M: MAKER: an easy-to-use annotation pipeline designed for emerging model organism genomes. Genome Res 2008, 18(1):188-196.

17. Robb SM, Ross E, Sánchez-Alvarado A: SmedGD: the Schmidtea mediterranea genome database. Nucleic Acids Res 2008, 36 Database: D599-606.

18. Emrich SJ, Barbazuk WB, Li L, Schnable PS: Gene discovery and annotation using LCM-454 transcriptome sequencing. Genome Res 2007, 17(1):69-73.

19. Abril JF, Castelo R, Guigo R: Comparison of splice sites in mammals and chicken. Genome Res 2005, 15(1):111-119.

20. Benson DA, Karsch-Mizrachi I, Lipman DJ, Ostell J, Sayers EW: GenBank. Nucleic Acids Res 2009, , 37 Database: D26-31.

21. Smed454 datasets web site. [http://planarian.bio.ub.es/datasets/454/].

22. Ashburner M, Ball CA, Blake JA, Botstein D, Butler H, Cherry JM, Davis AP, Dolinski K, Dwight SS, Eppig JT, et al: Gene ontology: tool for the unification of biology. The Gene Ontology Consortium. Nat Genet 2000, 25(1):25-29.

23. Hatfield DL: Selenium: Its Molecular Biology and Role in Human Health. Dordrecht: Kluwer Academic Publishers; 2001.

24. Castellano S, Novoselov SV, Kryukov GV, Lescure A, Blanco E, Krol A, Gladyshev VN, Guigo R: Reconsidering the evolution of eukaryotic selenoproteins: a novel nonmammalian family with scattered phylogenetic distribution. EMBO Rep 2004, 5(1):71-77.

25. Eisenhoffer GT, Kang H, Sánchez-Alvarado A: Molecular analysis of stem cells and their descendants during cell turnover and regeneration in the planarian Schmidtea mediterranea. Cell Stem Cell 2008, 3(3):327-339.

26. Rossi L, Salvetti A, Marincola FM, Lena A, Deri P, Mannini L, Batistoni R, Wang E, Gremigni V: Deciphering the molecular machinery of stem cells: a look at the neoblast gene expression profile. Genome Biol 2007, 8(4):R62.

27. Meinicke P: UFO: a web server for ultra-fast functional profiling of whole genome protein sequences. BMC Genomics 2009, 10:409.

28. Bonuccelli L, Rossi L, Lena A, Scarcelli V, Rainaldi G, Evangelista M, lacopetti P, Gremigni V, Salvetti A: An RbAp48-like gene regulates adult stem cells in planarians. J Cell Sci 2010, 123(Pt 5):690-698.

29. Guo T, Peters AH, Newmark PA: A Bruno-like gene is required for stem cell maintenance in planarians. Dev Cell 2006, 11(2):159-169.

30. Pearson BJ, Sánchez-Alvarado A: A planarian p53 homolog regulates proliferation and self-renewal in adult stem cell lineages. Development 2010, 137(2):213-221

31. Reddien PW, Oviedo NJ, Jennings JR, Jenkin JC, Sánchez-Alvarado A: SmedWI-2 is a PIWI-like protein that regulates planarian stem cells. Science 2005, 310(5752):1327-1330.

32. Franquinet $R$ : [The role of serotonin and catecholamines in the regeneration of the Planaria Polycelis tenvis]. J Embryol Exp Morphol 1979, 51:85-95.

33. Franquinet $R$, Martelly I: Effects of serotonin and catecholamines on RNA synthesis in planarians; in vitro and in vivo studies. Cell Differ 1981, 10(4):201-209.

34. Franquinet R, Le Moigne A, Hanoune J: The adenylate cyclase system of planaria Polycelis tenuis: activation by serotonin and guanine nucleotides. Biochim Biophys Acta 1978, 539(1):88-97.

35. Baguñà J, Saló E, Romero R: Effects of activators and antagonists of the neuropeptides substance $P$ and substance $K$ on cell proliferation in planarians. Int J Dev Biol 1989, 33(2):261-266.

36. Bautz A, Schilt J: Somatostatin-like peptide and regeneration capacities in planarians. Gen Comp Endocrinol 1986, 64(2):267-272.

37. Kreshchenko ND: Functions of flatworm neuropeptides NPF, GYIRF and FMRF in course of pharyngeal regeneration of anterior body fragments of planarian, Girardia tigrina. Acta Biol Hung 2008, 59(Suppl):199-207.

38. García-Fernández J, Baguñà J, Saló E: Planarian homeobox genes: cloning, sequence analysis, and expression. Proc Natl Acad Sci USA 1991, 88(16):7338-7342. 
39. Saló E, Baguñà J: Regeneration in planarians and other worms: New findings, new tools, and new perspectives. J Exp Zool 2002, 292(6):528-539.

40. Saló E, Tauler J, Jiménez E, Bayascas JR, González J, García-Fernàndez J, Baguñà J: Hox and parahox genes in flatworms: characterization and expression. Amer Zool 2001, 41:652-663.

41. Bayascas JR, Castillo E, Saló E: Platyhelminthes have a hox code differentially activated during regeneration, with genes closely related to those of spiralian protostomes. Dev Genes Evol 1998, 208(8):467-473.

42. Nogi T, Watanabe K: Position-specific and non-colinear expression of the planarian posterior (Abdominal-B-like) gene. Dev Growth Differ 2001, 43(2):177-184

43. Orii $\mathrm{H}$, Kato K, Umesono $\mathrm{Y}$, Sakurai T, Agata K, Watanabe K: The planarian HOM/HOX homeobox genes (Plox) expressed along the anteroposterior axis. Dev Biol 1999, 210(2):456-468.

44. Iglesias M, Gómez-Skarmeta JL, Saló E, Adell T: Silencing of Smedbetacatenin 1 generates radial-like hypercephalized planarians. Development 2008, 135(7):1215-1221.

45. Saló E, Batistoni R: The planarian eye: a simple and plastic system with great regenerative capacity. Animal models in eye research Tsonis PA: Academic Press; 2008, 15-26.

46. Saló E, Pineda D, Marsal M, González J, Gremigni V, Batistoni R: Genetic network of the eye in Platyhelminthes: expression and functional analysis of some players during planarian regeneration. Gene 2002, 287:67-74

47. Gehring WJ: New perspectives on eye development and the evolution of eyes and photoreceptors. J Hered 2005, 96(3):171-184

48. Gehring WJ, Ikeo K: Pax 6: mastering eye morphogenesis and eye evolution. Trends Genet 1999, 15(9):371-377.

49. Silver SJ, Rebay I: Signaling circuitries in development: insights from the retinal determination gene network. Development 2005, 132(1):3-13.

50. Treisman JE: A conserved blueprint for the eye? Bioessays 1999, 21(10):843-850.

51. Mannini L, Rossi L, Deri P, Gremigni V, Salvetti A, Saló E, Batistoni R: Djeyes absent (Djeya) controls prototypic planarian eye regeneration by cooperating with the transcription factor Djsix-1. Dev Biol 2004 269(2):346-359.

52. Pineda D, González J, Callaerts P, Ikeo K, Gehring WJ, Saló E: Searching for the prototypic eye genetic network: Sine oculis is essential for eye regeneration in planarians. Proc Natl Acad Sci USA 2000, 97(9):4525-4529.

53. Pineda D, González J, Marsal M, Saló E: Evolutionary conservation of the initial eye genetic pathway in planarians. Belg J Zool 2001, 131:77-82.

54. Pineda D, Rossi L, Batistoni R, Salvetti A, Marsal M, Gremigni V, Falleni A, González-Linares J, Deri P, Saló E: The genetic network of prototypic planarian eye regeneration is Pax6 independent. Development 2002, 129(6):1423-1434.

55. Inoue T, Kumamoto H, Okamoto K, Umesono Y, Sakai M, SánchezAlvarado A, Agata K: Morphological and functional recovery of the planarian photosensing system during head regeneration. Zoolog Sci 2004, 21(3):275-283.

56. Cebrià F, Newmark PA: Planarian homologs of netrin and netrin receptor are required for proper regeneration of the central nervous system and the maintenance of nervous system architecture. Development 2005, 132(16):3691-3703.

57. Sánchez Alvarado A, Newmark PA: Double-stranded RNA specifically disrupts gene expression during planarian regeneration. Proc Natl Acad Sci USA 1999, 96(9):5049-5054.

58. Takano T, Pulvers JN, Inoue T, Tarui H, Sakamoto H, Agata K, Umesono Y: Regeneration-dependent conditional gene knockdown (Readyknock) in planarian: Demonstration of requirement for Djsnap-25 expression in the brain for negative phototactic behavior. Dev Growth Differ 2007, 49(5):383-394.

59. Handberg-Thorsager M, Saló E: The planarian nanos-like gene Smednos is expressed in germline and eye precursor cells during development and regeneration. Dev Genes Evol 2007, 217(5):403-411.

60. Chevreux B: MIRA: An automated genome and EST assembler. Duisburg: Heidelberg; 2005.

61. Kent WJ: BLAT-the BLAST-like alignment tool. Genome Res 2002 12(4):656-664

62. exonerate: A generic tool for sequence alignment. [http://www.ebi.ac uk/ guy/exonerate/].
63. Altschul SF, Gish W, Miller W, Myers EW, Lipman DJ: Basic local alignment search tool. J Mol Biol 1990, 215(3):403-410.

64. Götz S, García-Gómez JM, Terol J, Williams TD, Nagaraj SH, Nueda MJ, Robles M, Talón M, Dopazo J, Conesa A: High-throughput functional annotation and data mining with the Blast2GO suite. Nucleic Acids Res 2008, 36(10):3420-3435.

65. Rice P, Longden I, Bleasby A: EMBOSS: the European Molecular Biology Open Software Suite. Trends Genet 2000, 16(6):276-277.

66. Almen MS, Nordstrom KJ, Fredriksson R, Schioth HB: Mapping the human membrane proteome: a majority of the human membrane proteins can be classified according to function and evolutionary origin. BMC Biol 2009, 7:50

67. Kall L, Krogh A, Sonnhammer EL: Advantages of combined transmembrane topology and signal peptide prediction-the Phobius web server. Nucleic Acids Res 2007, , 35 Web Server: W429-432

68. Krogh A, Larsson B, von Heijne G, Sonnhammer EL: Predicting transmembrane protein topology with a hidden Markov model: application to complete genomes. J Mol Biol 2001, 305(3):567-580.

69. Hirokawa T, Boon-Chieng S, Mitaku S: SOSUl: classification and secondary structure prediction system for membrane proteins. Bioinformatics 1998, 14(4):378-379

70. Ahram M, Litou ZI, Fang R, Al-Tawallbeh G: Estimation of membrane proteins in the human proteome. In Silico Biol 2006, 6(5):379-386.

71. Hintze JL, Nelson RD: Violin plots: a box plot-density trace synergism. The American Statistician 1998, 52(2):181-184.

doi:10.1186/1471-2164-11-731

Cite this article as: Abril et al:: Smed454 dataset: unravelling the transcriptome of Schmidtea mediterranea. BMC Genomics 2010 11:731.

\section{Submit your next manuscript to BioMed Central and take full advantage of:}

- Convenient online submission

- Thorough peer review

- No space constraints or color figure charges

- Immediate publication on acceptance

- Inclusion in PubMed, CAS, Scopus and Google Scholar

- Research which is freely available for redistribution

Submit your manuscript at www.biomedcentral.com/submit
C Biomed Central 